University of New Hampshire

University of New Hampshire Scholars' Repository

$6-2010$

\title{
Interannual, seasonal, and diel variation in soil respiration relative to ecosystem respiration at a wetland to upland slope at Harvard Forest
}

\author{
Stephen C. Phillips \\ University of New Hampshire - Main Campus \\ Ruth Varner \\ University of New Hampshire - Main Campus, ruth.varner@unh.edu \\ Steve Frolking \\ University of New Hampshire - Main Campus, steve.frolking@unh.edu \\ J W. Munger \\ Harvard University \\ Jill L. Bubier \\ Mount Holyoke College
}

See next page for additional authors

Follow this and additional works at: https://scholars.unh.edu/earthsci_facpub

\section{Recommended Citation}

Phillips, S. C., R. K. Varner, S. Frolking, J. W. Munger, J. L. Bubier, S. C. Wofsy, and P. M. Crill (2010), Interannual, seasonal, and diel variation in soil respiration relative to ecosystem respiration at a wetland to upland slope at Harvard Forest, J. Geophys. Res., 115, G02019, doi:10.1029/2008JG000858

This Article is brought to you for free and open access by the Earth Sciences at University of New Hampshire Scholars' Repository. It has been accepted for inclusion in Earth Sciences Scholarship by an authorized administrator of University of New Hampshire Scholars' Repository. For more information, please contact Scholarly.Communication@unh.edu. 


\section{Authors}

Stephen C. Phillips, Ruth Varner, Steve Frolking, J W. Munger, Jill L. Bubier, P Crill, and Steven C. Wofsy 


\title{
Interannual, seasonal, and diel variation in soil respiration relative to ecosystem respiration at a wetland to upland slope at Harvard Forest
}

\author{
Stephen C. Phillips, ${ }^{1}$ Ruth K. Varner, ${ }^{1}$ Steve Frolking, ${ }^{1}$ J. William Munger, ${ }^{2}$ \\ Jill L. Bubier, ${ }^{3}$ Steven C. Wofsy, ${ }^{2}$ and Patrick M. Crill ${ }^{4}$ \\ Received 12 September 2008; revised 26 November 2009; accepted 28 January 2010; published 16 June 2010.
}

[1] Soil carbon dioxide efflux (soil respiration, SR) was measured with eight autochambers at two locations along a wetland to upland slope at Harvard Forest over a 4 year period, 2003-2007. SR was consistently higher in the upland plots than at the wetland margin during the late summer/early fall. Seasonal and diel hystereses with respect to soil temperatures were of sufficient magnitude to prevent quantification of the influence of soil moisture, although apparent short-term responses of SR to precipitation occurred. Calculations of annual cumulative SR illustrated a decreasing trend in SR over the 5 year period, which were correlated with decreasing springtime mean soil temperatures. Spring soil temperatures decreased despite rising air temperatures over the same period, possibly as an effect of earlier leaf expansion and shading. The synchronous decrease in spring soil temperatures and SR during regional warming of air temperatures may represent a negative feedback on a warming climate by reducing $\mathrm{CO}_{2}$ production from soils. SR reached a maximum later in the year than total ecosystem respiration (ER) measured at a nearby eddy covariance flux tower, and the seasonality of their temperature response patterns were roughly opposite. SR, particularly in the upland, exceeded ER in the late summer/early fall in each year, suggesting that areas of lower efflux such as the wetland may be significant in the flux tower footprint or that long-term bias in either estimate may create a mismatch. Annual estimates of ER decreased over the same period and were highly correlated with SR.

Citation: Phillips, S. C., R. K. Varner, S. Frolking, J. W. Munger, J. L. Bubier, S. C. Wofsy, and P. M. Crill (2010), Interannual, seasonal, and diel variation in soil respiration relative to ecosystem respiration at a wetland to upland slope at Harvard Forest, J. Geophys. Res., 115, G02019, doi:10.1029/2008JG000858.

\section{Introduction}

[2] Exchange of carbon dioxide $\left(\mathrm{CO}_{2}\right)$ between forest ecosystems and the atmosphere is an important component of the global carbon cycle. Soil organic matter (SOM) comprises a significant terrestrial reservoir of carbon [Post et al., 1982] that contains approximately twice the carbon present in the atmosphere and stored within a few meters of the atmosphere [Jobbagy and Jackson, 2000]. Investigations into imbalances in the global carbon cycle suggest that terrestrial ecosystems of the northern hemisphere may be a net sink of

\footnotetext{
${ }^{1}$ Institute for the Study of Earth, Oceans, and Space, and Department of Earth Sciences, University of New Hampshire, Durham, New Hampshire, USA.

${ }^{2}$ School of Engineering and Applied Sciences, Harvard University, Cambridge, Massachusetts, USA.

${ }^{3}$ Environmental Studies Program, Mount Holyoke College, South Hadley, Massachusetts, USA.

${ }^{4}$ Department of Geology and Geochemistry, Stockholm University, Stockholm, Sweden.

Copyright 2010 by the American Geophysical Union. 0148-0227/10/2008JG000858
}

carbon with respect to the atmosphere [Tans et al., 1990; Keeling et al., 1996; Schimel et al., 2001].

[3] Efforts to measure net ecosystem exchange (NEE) of $\mathrm{CO}_{2}$ in various ecosystems have resulted in the installation of micrometeorological flux towers around the world (FLUXNET, see http://www-eosdis.ornl.gov/fluxnet/). Results from these eddy covariance (EC) measurements in a variety of forest ecosystems have demonstrated an important effect of climate and vegetation on ecosystem fluxes over a range of timescales [Wofsy et al., 1993; Goulden et al., 1996a; Baldocchi et al., 1997; Black et al., 2000; Curtis et al., 2002; Barford et al., 2001; Carrara et al., 2003; Griffis et al., 2003; Morgenstern et al., 2004; Saigusa et al., 2005; Desai et al., 2008].

[4] NEE measurements at zero photosynthetically active radiation (PAR) have been used to estimate total ecosystem respiration (ER). Nighttime NEE values are therefore used to partition daytime NEE measurements into gross primary production (GPP) and ER components. However, EC tower measurements are most uncertain at night due to lowturbulence conditions [Goulden et al., 1996a]. Yet, ER may be the primary determinant of interannual variability 
of the net carbon exchange of temperate forests [Valentini et al., 2000; Ehman et al., 2002].

[5] More than ten years of EC measurements from Harvard Forest suggest that this forest has been a net sink of atmospheric $\mathrm{CO}_{2}$ over this period, with annual uptake ranging from 1.0 to $4.7 \mathrm{Mg}-\mathrm{C} \mathrm{ha}{ }^{-1} \mathrm{yr}^{-1}$, with interannual variability controlled by climate and ecosystem factors [Wofsy et al., 1993; Goulden et al., 1996b; Barford et al., 2001; Urbanski et al., 2007]. Net uptake increased over a time period from 1992 to 2004, with both GPP and ER increasing over the measurement period; however, GPP increased to a larger extent than ER, resulting in increasing net uptake [Urbanski et al., 2007]. Tower eddy covariance ER cannot be partitioned into autotrophic and heterotrophic components, nor can it be separated into aboveground and belowground components.

[6] In this paper "soil respiration" refers to total soil efflux. Soil respiration (SR) results from the combined respiration of free-living soil microbes and roots including mycorrhizal symbionts. Root exclusion and isotopic labeling studies indicate that root respiration (including rhizosphere activity) contribute significantly (10-90\%) to the total SR in forests [Hanson et al., 2000]. At Harvard Forest, the combined contribution of live root respiration and root litter decomposition to SR was estimated to be $63 \%$ at the DIRT plot experiments [Bowden et al., 1993]. In this paper "soil respiration" refers to total soil efflux.

[7] SR and SOM turnover rates are positively correlated with soil temperature on annual timescales [Raich and Schlesinger, 1992; Trumbore et al., 1996]. Soil warming experiments have shown that, on timescales shorter than a decade, warmer soil temperatures increase SR, net nitrogenmineralization rates, and plant productivity, but that this effect is transient [Rustad et al., 2001]. No consensus has yet been reached over the long-term soil respiration response to temperature, due to the complexity and heterogeneity of soil organic carbon and variety of soil factors [Davidson et al., 2000; Davidson and Janssens, 2006]. Root respiration appears to be more sensitive to temperature than nonrhizosphere microbial respiration due to the influence of phenology [Boone et al., 1998].

[8] Soil moisture is an important control on SR, with increases occurring during and after wetting events [Borken et al., 2003; Lee et al., 2004], and decreased SR in upland sites during natural and simulated droughts [Savage and Davidson, 2001; Borken et al., 2006]. Drought affects the root component of SR [Burton et al., 1998] but the heterotrophic component is affected more strongly. Statistically separating the temperature and soil moisture effect on SR can be difficult because temperature and soil moisture are correlated over a seasonal timescale [Davidson et al., 2002].

[9] High-resolution, semicontinuous soil surface $\mathrm{CO}_{2}$ flux data from autochambers along with other concurrent data (temperature, soil moisture, precipitation, etc.) at the same sites, provide an excellent opportunity to observe and evaluate changes in SR on shorter timescales than manual sampling intervals. Autochambers allow for better accuracy in creating empirical models of the effects of temperature and soil moisture on soil respiration compared to manual chambers [Savage and Davidson, 2003]. Manual and automatic chamber measurements at a single site have been shown to be consistent [Burrows et al., 2005]. Scaling chamber SR mea- surements to tower ER measurements has produced mixed results due to uncertainty in assumptions about aboveground respiratory processes and the tower's flux footprint [Loescher et al., 2006].

[10] We analyzed SR data measured by a cluster of autochambers on a wetland to upland hillslope at Harvard Forest for seasonal and interannual variation, as well as the effect of chamber location. The autochambers were set up to record high-frequency measurements of SR at two site types that likely exist within the EC tower flux footprint. The relationship of SR with temperature and soil moisture was explored on interannual, seasonal, and diel timescales. SR measurements were compared qualitatively to ER measurements at the EC tower. Interannual changes in ER and SR were analyzed relative to climatic and phenological data as a potential feedback on climate.

\section{Methods}

\subsection{Site Description}

[11] The Harvard Forest Environmental Measurement Site (HFEMS), part of the Harvard Forest Long-Term Ecological Research (LTER) site, located in Petersham, MA $\left(42^{\circ} 54^{\prime} \mathrm{N}\right.$ $\left.72^{\circ} 17^{\prime}\right)$, is a $50-70$ year old second-growth mixed forest located on former agricultural land that is typical for New England forests [Foster, 1992]. The dominant tree species are red oak (Quercus rubra) and red maple (Acer rubrum), with smaller numbers of white pine (Pinus strobus) and eastern hemlock (Tsuga canadensis). An eddy covariance flux tower is located at the HFEMS site in the Prospect Hill Tract and has been measuring NEE since 1990 [e.g., Urbanski et al., 2007].

\subsection{Instrumentation}

[12] The overall measurement objective was to examine high-frequency variability in SR and its response to environmental drivers along a moisture gradient within the ecosystem observed by the HFEMS tower. A system of eight opaque automatic $\mathrm{CO}_{2}$ flux chambers was installed approximately $500 \mathrm{~m}$ northwest of the flux tower at the EMS site in April 2003. The autochambers were operated from April through November 2003, and April through December during 2004-2007. The landscape surrounding the EMS flux tower within $50-500 \mathrm{~m}$ in the NW to SW predominant wind direction that contributes to the observed flux measurements contains a heterogeneous mix of drainage conditions. Wet and dry patches occur across a wide range of scale from humps and hollows of several meters in size to a $500 \mathrm{~m}$ by $200 \mathrm{~m}$ pond and wetland to the NW of the tower. We selected a site on the east side of the pond where the autochamber system could access the full moisture gradient. This location is on the edge of the dominant upwind sector for the EMS tower so occasionally contributes to the observed fluxes. More importantly, the autochamber transect captures the range of moisture conditions across the rest of the landscape within the flux footprint and has similar soils and vegetation.

[13] The objective of the autochamber measurements was not to scale directly to the tower observations, but to examine the response of soil respiration to driving variables and better understand the underlying mechanisms that are operating within this ecosystem. Given the fine-scale heterogeneity in the landscape that is not adequately represented 
Table 1. Chamber Locations With Distance to and Elevation Above Wetland Margin

\begin{tabular}{lccc}
\hline \multicolumn{1}{c}{ Location } & Chamber & Distance $(\mathrm{m})$ & Elevation $(\mathrm{m})$ \\
\hline Upland & 1 & 19 & 1.0 \\
& 2 & 16 & 1.7 \\
& 3 & 13 & 1.1 \\
Wetland Margin & 4 & 11 & 0.7 \\
& 5 & 3 & 0.4 \\
& 6 & 3 & 0.2 \\
& 7 & 2 & 0.2 \\
\hline
\end{tabular}

in soil and drainage classification maps and footprint models and uncertainty in treatment of subcanopy mixing [Rannik et al., 2003; Schmid, 2002], a detailed flux footprint analysis has not been undertaken for the HFEMS tower. The soils and vegetation present at the autochamber site are consistent with that across the rest of the landscape upwind of the tower. The trends observed by the chambers, which are the focus of this paper, should be representative of the range of soil respiration responses across the ecosystem observed by the flux tower.

[14] The autochambers sampled two locations along a moisture gradient from the edge of a wetland to upland forest (Table 1). The bottom of the slope is characterized by poorly drained wetland soil. Soils at the top of the slope are well drained upland at an elevation $1 \mathrm{~m}$ higher than wetland margin. Wetland margin soils contain a litter layer of approximately $2.5 \mathrm{~cm}$ and an $\mathrm{O}$ horizon of approximately $16 \mathrm{~cm}$. Litter and organic layers at the upland chambers are thinner, $1-2 \mathrm{~cm}$ and $5 \mathrm{~cm}$, respectively.

[15] The system at Harvard Forest was based on automated soil flux instrumentation previously used in a boreal forest [Goulden and Crill, 1997], a tropical agricultural soil [Crill et al., 2000], and a temperate peatland [Bubier et al., 2003]. Fixed constant volumes were assumed for each chamber. Each aluminum opaque chamber enclosed a volume of $0.0381 \mathrm{~m}^{3}(0.432 \mathrm{~m} \times 0.432 \mathrm{~m} \times 0.152 \mathrm{~m})$ and covered an area of $0.187 \mathrm{~m}^{2}$. The chamber closed over a metal frame that extends $2 \mathrm{~cm}$ into mainly bare soil, with minimal vegetation present in the chamber. Air from the chamber headspace was pumped through an infrared $\mathrm{CO}_{2}$ gas analyzer (IRGA, Model LI-820, Li-Cor, Lincoln, Nebraska) and the air was then returned to the chamber at approximately $700 \mathrm{ml} \mathrm{min}{ }^{-1}$. The length of tubing varied between 25 and $50 \mathrm{~m}$ depending on the location of the chamber. We calculated the residence time in the tubing as less than $4 \mathrm{~min}$. The system volume was calculated as the chamber volume plus the volume of tubing and the control system. Collar height or distance from the soil surface to the top of the collar was measured to determine the chamber volume. Changes in pressure can disturb the natural exchange of gas between the soil and atmosphere [Bain et al., 2005; Davidson et al., 2002], thus causing error in flux calculations. Pressure relief ports and perforated manifolds for return flow were included in the design to minimize pressure artifacts while ensuring more uniform mixing in the chambers. Air inflow and outflow rates were balanced and chamber closure produced an increase of less than $10 \mathrm{~Pa}$ lasting shorter than $2 \mathrm{~s}$ in duration. Water seals were kept intact by biweekly inspections in the field.

[16] The measurement system was controlled by a data logger (CR10X, Campbell Scientific, Logan, UT) and 16-port relay that drove valves to pneumatically open and close the chambers. Each measurement cycle took $30 \mathrm{~min}$, including time to flush the transfer tubing (10 min before and $12 \mathrm{~min}$ after each 8 min closure time). Consequently, a flux was recorded at each autochamber every $4 \mathrm{~h}$. Five linear fits over a $2.5 \mathrm{~min}$ period were measured and the maximum slope was recorded and used to calculate the flux [Bubier et al., 2003]. A minimum $\mathrm{R}^{2}$ of 0.85 in the linear fit of $\mathrm{CO}_{2}$ mixing ratios versus time was set as criteria for accepting fluxes.

[17] Each chamber had thermocouples measuring chamber air and $2 \mathrm{~cm}$ litter depth temperatures. Additional soil temperature and soil moisture instruments at three soil profiles were installed in May 2004 (wetland margin, midslope, and upland soils) in the base of the litter and organic horizons and in the mineral soil. The data were recorded as hourly averages of $1 \mathrm{~min}$ observations. Soil temperatures were measured using thermocouple probes (Type-T thermocouples, Omega Engineering, Stamford, CT) and soil moisture were measured with time domain reflectometry (TDR) probes $\left(\mathrm{ECH}_{2} \mathrm{O}\right.$ probes, Decagon Devices, Inc., Pullman, WA). Due to technical setbacks, soil moisture data at the profiles was only available for 2004 and part of 2007. As a result of missing data, we incorporated into our analyses TDR soil moisture measurements from $50 \mathrm{~m}$ northwest of the tower at depths of 5, 9, 26 and $85 \mathrm{~cm}$ (E. Davidson and K. Savage, unpublished data, 2010).

\subsection{Data Analysis}

[18] All data were analyzed using Matlab 7.1 (Mathworks, Natick, MA) and JMP 6.0.2 (SAS Institute, Inc., Cary, NC). The flux measurements were filtered to remove near-zero measurements when the IRGA was not operating, or negative flux values (we assume there is no $\mathrm{CO}_{2}$ uptake in an opaque chamber on nearly bare ground). A flux detection limit of $0.024 \mu \mathrm{mol} \mathrm{CO} 2 \mathrm{~m}^{-2} \mathrm{~s}^{-\mathrm{P}}$ was determined using the stated precision of the IRGA instrument of $1 \mu \mathrm{mol} / \mathrm{mol}$, and the minimum detectable slope that is significantly larger than zero, given the volume and area of the chambers. All fluxes below this threshold were removed before data analysis, as a means of removing flux data recorded when the chambers were not closing due to compressor failure and pneumatic line breakage. For most of the measurement period near-zero fluxes were outliers, and we discuss potential biases from the removal of these fluxes in section 4. Additional fluxes were removed due to low flow values in the IRGA, and unreasonable temperature values. Autochamber data were grouped into two locations according to slope position (wetland margin and upland; Table 1).

\subsection{Gap Filling}

[19] Daily averages were the basis for all empirical relationships in gap filling due to the presence of diel patterns in SR (see sections 3 and 4). Missing temperature measurements were filled using $15 \mathrm{~cm}$ soil temperatures measured at the HFEMS meteorological station approximately $1 \mathrm{~km}$ from the autochambers. Relationships relating SR to soil temperature at each chamber in each year were derived by fitting an Arrhenius equation to the natural $\log$ of the SR data and inverse of the soil temperature:

$$
S R=A e^{\frac{-E a}{R T}}
$$


where $E_{a}$ is the activation energy, $R$ is the gas constant $\left(8.314 \mathrm{~J} \mathrm{~mol}^{-1} \mathrm{~K}^{-1}\right), T$ is the soil temperature $(\mathrm{K})$, and $A$ is a base respiration. Uncertainties in the fit parameters were estimated using a bootstrapping method to calculate $95 \%$ confidence intervals [Efron and Tibshirani, 1986]. Equation (1) was fit to random $10 \%$ subsets of the data through 1000 iterations to generate a normal distribution to calculate confidence intervals.

[20] Soil temperatures at $2 \mathrm{~cm}$ depth were used for temperature regressions. The $2 \mathrm{~cm}$ soil temperature is representative of the temperature conditions in the organic soil and litter, as most of the SOM is located within $5 \mathrm{~cm}$ of the surface in upland soils. This is consistent with studies that partition the sources of $\mathrm{CO}_{2}$ in the soil, where a significant fraction of SR is attributed to both the O horizon (40-48\%) [Davidson et al., 2006b] and litter layer (0-42\% depending on moisture conditions) [Cisneros-Dozal et al., 2006].

[21] Residuals from the yearlong temperature regression were fit with a cubic polynomial function to model the nontemperature seasonal variation due to hysteresis:

$$
R=\beta_{0} d^{3}+\beta_{1} d^{2}+\beta_{2} d+\beta_{3}
$$

where $R$ is the residual, $B_{0}, B_{1}, B_{2}$, and $B_{3}$ are coefficients and $d$ is the day of the year. Equations (1) and (2) were fit for each chamber separately for each year. Residuals were fit using this function to account for seasonal variation as soil moisture did not correlate with this variation. Missing SR measurements were filled as daily averages by the sum of the temperature regression and the residual regression.

\subsection{Annual Estimates of SR and ER}

[22] Estimates of annual carbon release were calculated by summation of individual SR measurements weighted by their representative period $(4 \mathrm{~h}$ between measurements or gap-filled daily value). Uncertainty from the $95 \%$ confidence intervals was summed in quadrature to produce an error estimate for the annual carbon values.

[23] Gap-filled tower ER was used in the analysis (see section 4.4). ER data were prepared using a temperature fit algorithm described by Urbanski et al. [2007], and are available at the Harvard Forest Data Archive (http://harvardforest. fas.harvard.edu/data/p00/hf004/HF004-data.html). Gap-filled tower ER data were summed based on the hourly averages present in the data set. ER data from 2005 were excluded from analysis due to extended gaps caused by a lightning strike. Time series of SR were qualitatively compared to ER from the eddy covariance flux tower in the years 2003-2004, and 2006-2007.

\section{Results}

\subsection{Data}

[24] A total of 39,695 soil flux measurements were used in this analysis (Figure 1). Electrical or mechanical disruptions resulted in simultaneous gaps in all eight chambers. Periods of near-zero or negative fluxes corresponded to time periods when the system was known to be not working. These gap fractions were 0.01 in 2003 and 2004, 0.11 in 2005, 0.20 in 2006, and 0.27 in 2007. Most of the removed fluxes correspond to times when a chamber was not closing properly, as noted from periodic field visits. Total gap fraction including both power disruptions and loss of pneumatic pressure was $0.30,0.11,0.32,0.26$, and 0.42 in 2003, 2004, 2005, 2006, and 2007, respectively (Figure 1). The autochamber SR data are available at the Harvard Forest Data Archive (http://harvardforest.fas.harvard.edu/ data/p06/hf068/hf068.html).

\subsection{Comparison by Slope Location}

[25] The highest average SR fluxes were recorded at the upland chambers, and the lowest fluxes at the wetland margin (Table 2). The differences between the chamber groupings were more pronounced in the years 2004, 2005, and 2006. SR flux variability was greatest in 2004 and 2005. Time series of the flux data illustrates the seasonal variation in SR and variation between locations (Figure 1). Upland and wetland margin fluxes were highly correlated but the upland consistently measured a higher magnitude of SR.

\subsection{Seasonal Patterns}

[26] There was a distinct seasonal hysteresis when monthly average fluxes were plotted against monthly average $2 \mathrm{~cm}$ soil temperature (Figure 2). SR at both chamber locations was higher at a given temperature in the late summer than in the spring. Residuals from a fit of the Arrhenius function (equation (1)) to monthly average $2 \mathrm{~cm}$ temperature and SR were negative early in the growing season, positive later in the season, and returned to negative in the late fall. The seasonal pattern was diminished in 2005; average soil moisture in 2005 was similar to that in 2004, but data gaps preclude thorough analysis of this. Average $5 \mathrm{~cm}$ soil moisture near the tower was $0.22,0.26,0.26$, and $0.23 \mathrm{~cm}^{3} \mathrm{~cm}^{-3}$ in 2003, 2004, 2005, and 2006, respectively.

[27] The ratio of SR to ER from the years 2003, 2004, and 2006 showed a difference in the seasonal patterns (Figure 3). ER reached a peak early in the summer while SR was at a maximum later in the summer. Likewise, SR comprised a higher fraction of ER during the late summer/early fall in all years. Seasonal hysteresis in the tower ER data plotted against monthly $2 \mathrm{~cm}$ soil temperature at the upland chambers had roughly the reverse of the hysteresis of the SR (Figure 4). ER was higher in the spring/early summer than in the late summer/fall for a given soil temperature.

\subsection{Annual Estimates of $S R$ and ER}

[28] Annual estimates of SR carbon release are presented in Table 2. Annual $\mathrm{C}$ release ranged from 401 to $1250 \mathrm{~g} \mathrm{C} \mathrm{m}^{-2}$ $\mathrm{yr}^{-1}$ at upland chambers and 424 to $956 \mathrm{~g} \mathrm{C} \mathrm{m}^{-2} \mathrm{yr}^{-1}$ at wetland margin chambers. Average SR over the 5 year period was $819 \mathrm{~g} \mathrm{C} \mathrm{m}^{-2} \mathrm{yr}^{-1}$ at the upland and $627 \mathrm{~g} \mathrm{C} \mathrm{m}^{-2} \mathrm{yr}^{-1}$. Annual carbon release decreased over the 5 year measurement period at all chambers (Figure 5). Annual carbon release was generally lower at the wetland margin (average of $192 \mathrm{~g} \mathrm{C} \mathrm{m}^{-2} \mathrm{yr}^{-1}$ ) when compared to upland chambers, consistent with higher fluxes in the upland during late summer. Annual ER also decreased over 2003-2004 and 2006-2007.

[29] The effectiveness of the model was evaluated by utilizing the temperature fit and cubic fit of the residuals to predict observed daily averages (Figure 6). The mean absolute error (MAE) was calculated for each year and chamber 

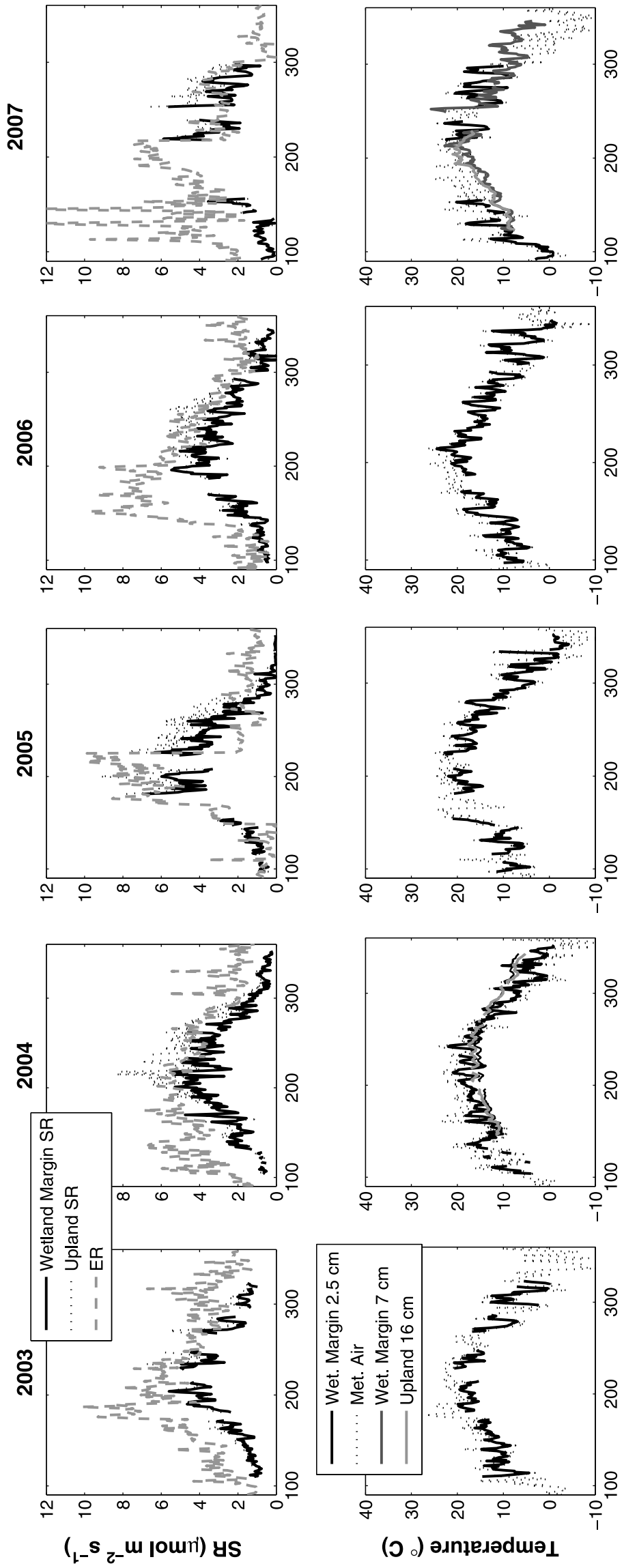

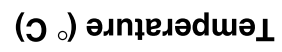

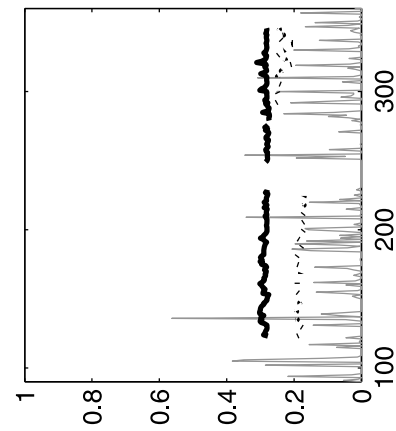

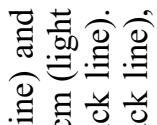

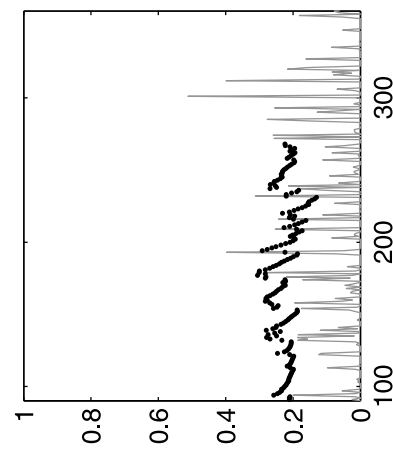

드름

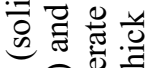

ชิ

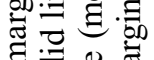

응 光

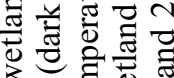

Ð

ฆ ำ

을.

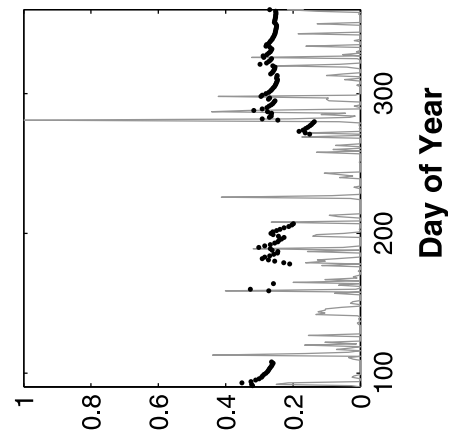

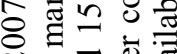

그 홏

츨

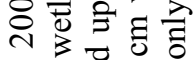

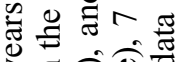

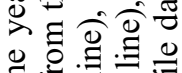

¿

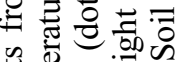

芑

ฮี

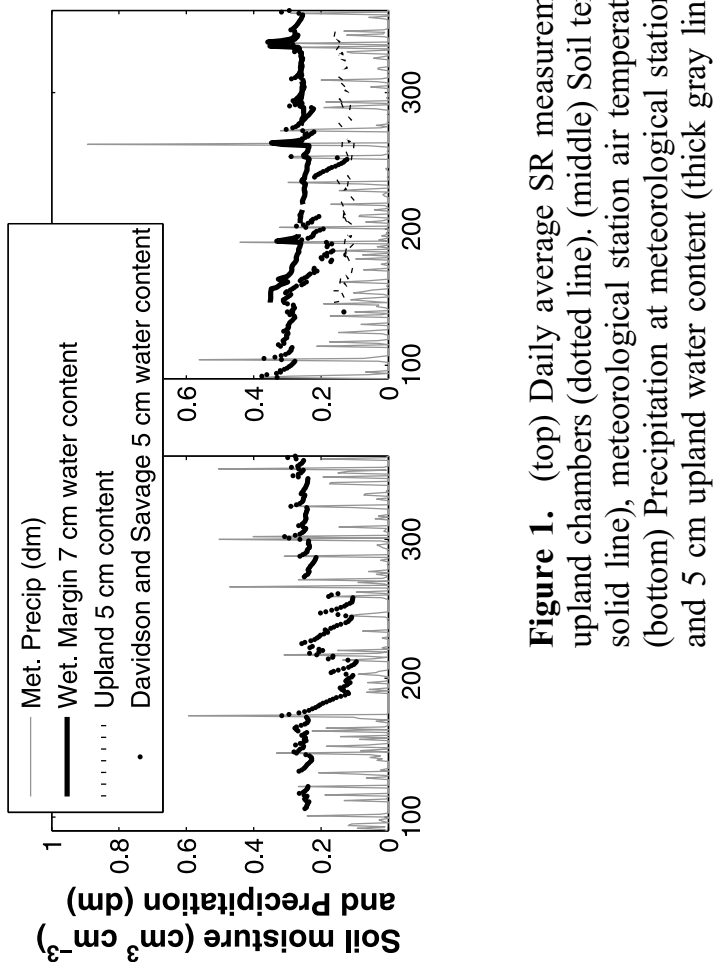


Table 2. Annual Estimate of SR $\pm 95 \%$ Confidence Intervals $^{\mathrm{a}}$

\begin{tabular}{cccccc}
\hline & \multicolumn{5}{c}{ Annual C Emission $\left(\mathrm{g} \mathrm{C} \mathrm{m}^{-2} \mathrm{~s}^{-1}\right)$} \\
\cline { 2 - 6 } Chamber & 2003 & 2004 & 2005 & 2006 & 2007 \\
\hline 1 & $810 \pm 8$ & $692 \pm 55$ & $648 \pm 32$ & $447 \pm 15$ & $468 \pm 16$ \\
2 & $928 \pm 11$ & $763 \pm 15$ & $845 \pm 14$ & $570 \pm 14$ & $401 \pm 21$ \\
3 & $884 \pm 16$ & $985 \pm 19$ & $1020 \pm 12$ & $910 \pm 17$ & $745 \pm 38$ \\
4 & $897 \pm 17$ & $941 \pm 13$ & $1114 \pm 7$ & $1053 \pm 8$ & $1250 \pm 31$ \\
5 & $726 \pm 23$ & $662 \pm 13$ & $652 \pm 48$ & $589 \pm 8$ & $424 \pm 85$ \\
6 & $956 \pm 33$ & $761 \pm 28$ & $746 \pm 14$ & $615 \pm 55$ & $648 \pm 25$ \\
7 & $667 \pm 36$ & $469 \pm 21$ & $649 \pm 11$ & $434 \pm 6$ & $436 \pm 41$ \\
8 & $658 \pm 10$ & $676 \pm 10$ & $630 \pm 16$ & $686 \pm 11$ & $447 \pm 25$ \\
\hline
\end{tabular}

${ }^{\mathrm{a}}$ Chambers $1-4$ are upland sites; chambers $5-8$ are wetland margin sites

(Table 3). Daily MAE varied between 0.38 and $1.3 \mu \mathrm{mol} \mathrm{m}^{-2}$ $\mathrm{s}^{-1}$ with an average of $0.64 \mu \mathrm{mol} \mathrm{m} \mathrm{m}^{-2} \mathrm{~s}^{-1}$. Inclusion of the polynomial fit of the residuals to account for seasonal hysteresis improved the ability of the model to predict individual values over a temperature-only regression. MAE decreased by $20-40 \%$ when the polynomial residual regression was included in the model.

[30] Uncertainties from bootstrapping extrapolated to calculate uncertainties in the annual estimates show that the temperature regression provided a good fit on annual scales. Uncertainty from daily $95 \%$ confidence intervals from bootstrapping on filled values and the mean of measured values, when summed with quadrature over 365 days, was below $85 \mathrm{~g} \mathrm{C} \mathrm{m}^{2} \mathrm{yr}^{-1}$.

\section{Discussion}

\subsection{Soil Respiration at Harvard Forest}

[31] SR rates are similar to rates measured by other automatic and manual systems at Harvard Forest, though with some differences depending on year and chamber location. Mean SR fluxes from late June to late August in 2002 reported by Savage and Davidson [2003] using manual and autochambers were $4.6 \pm 0.3$ and $4.6 \pm 0.5 \mu \mathrm{mol} \mathrm{m} \mathrm{m}^{-1}$, respectively. Our late-June to late-August flux averaged across all chambers was lower than this during 2003, 2004, and 2006, and higher in 2005, but not significantly different when averaged over all four years.

[32] When comparing each chamber group separately to the 2002 chamber measurements by Savage and Davidson [2003], SR from the upland chambers, averaged over 20032006 during the same June-August time period, was very

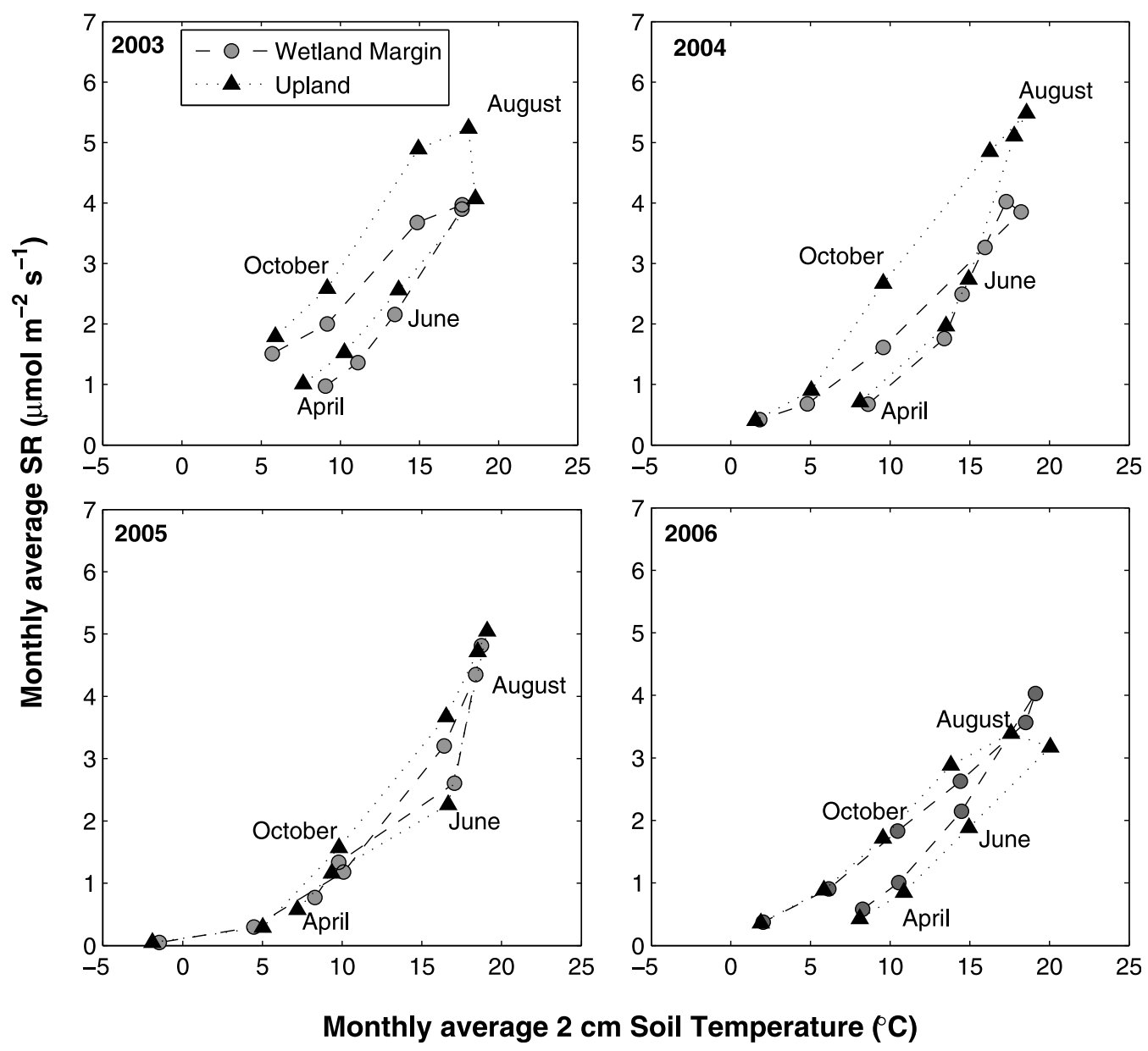

Figure 2. Monthly average soil temperature $(2 \mathrm{~cm})$ versus monthly average SR demonstrates a hysteresis in which there are higher fluxes for a given temperature in the fall than in the spring/early summer. The upland chambers (black triangles) follow a much stronger nontemperature driven variation than the wetland margin chambers (gray circles). 

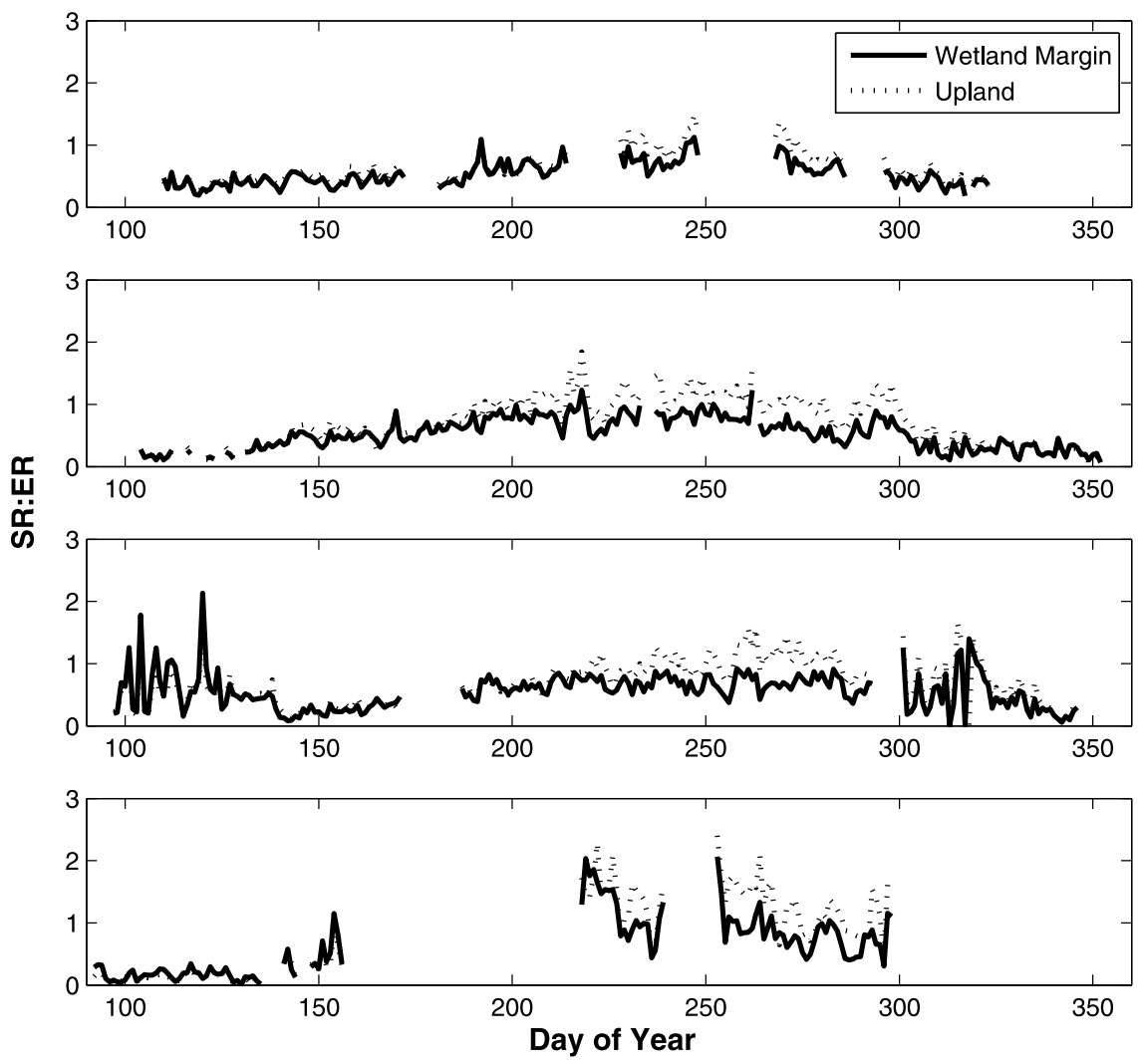

Figure 3. Ratio of chamber SR to tower ER for both the wetland margin (black solid line) and upland (gray dashed line) sites.

similar $\left(4.84 \pm 0.08 \mu \mathrm{mol} \mathrm{m} \mathrm{m}^{-1}\right)$, and the wetland was significantly lower $\left(4.03 \pm 0.04 \mu \mathrm{mol} \mathrm{m} \mathrm{m}^{-1}\right)$. These measurements at Harvard Forest are very similar to the average SR measured at a range of temperate mixed forest sites. Mean values for mixed forest biomes are $3.5 \pm 2.2$ and $4.9 \pm 1.1$ for annual and growing season, respectively [Hibbard et al., 2005].

[33] Differences in SR between the chamber groups may be explained by long-term moisture conditions. Wetland margin chambers measure the lowest fluxes in all years. In both years of soil moisture measurements the wetland margin experienced significantly higher water content. Mean wetland margin water content was 0.27 and $0.30 \mathrm{~cm}^{3} \mathrm{~cm}^{-3}$ and mean upland water content was 0.13 and 0.23 in 2004 and 2007, and $\mathrm{O}_{2}$ diffusion may be limiting oxic heterotrophy in the wetter sites. The depth of the $\mathrm{O}$ horizon is significantly deeper at the wetland margin $(18.75 \mathrm{~cm})$ than at the upland $(5 \mathrm{~cm})$ suggesting slower rates of decomposition given equal input rates, which would result in a long-term lower soil respiration. The litter layer is also deeper at the wetland margin $(2.5 \mathrm{~cm})$ than at the upland $(1$ and $1.25 \mathrm{~cm})$.

[34] Filtering by removing fluxes below the flux detection limit may introduce some bias into the data, because some of the low fluxes may be real. Fluxes were significantly larger than zero during most of the growing season, and a near-zero growing season flux is a good indication of a faulty measurement. Biases might be more important early or late in the measurement period when near-zero fluxes could be valid and would be excluded by the filter criteria. In 2003, 2004, 2006, and 2007 there was little seasonal variation in the percentage of fluxes removed by month. The November and December 2005 monthly mean SR was higher with below detection limit fluxes removed than the same monthly averages containing the low fluxes $(0.3 \mathrm{com}-$ pared to $0.2 \mu \mathrm{mol} \mathrm{m} \mathrm{m}^{2}$ ). Rejecting the low fluxes also decreased the standard deviation of SR during these months from 0.8 to $0.4 \mu \mathrm{mol} \mathrm{m}^{2} \mathrm{~s}^{-1}$. Filtering possibly caused a small overestimation of SR in these months; however, the magnitude of mean SR during these months was small regardless of the inclusion or exclusion of low fluxes. The observed annual patterns or observed seasonal hysteresis were not significantly affected by the truncation bias from removing very low fluxes that may have been valid.

\subsection{Diel Hysteresis}

[35] There was a distinct diel hysteresis in which SR was out of phase with respect to soil temperature and higher fluxes occur during the night than during the daytime for a given temperature (Figure 7). This effect is similar to that described by others [Hirsch et al., 2002; Hirano et al., 2003; Parkin and Kaspar, 2003; Tang et al., 2005; Liu et al., 2006; Gaumont-Guay et al., 2006a; Riveros-Iregui et al., 2007; Carbone et al., 2008]. The magnitude of hysteresis was calculated based on the range of residuals from the linear regression of $2 \mathrm{~cm}$ temperature $(T)$ and SR for each day based on Riveros-Iregui et al. [2007]:

$$
S R=\beta_{0} T+\beta_{1}
$$



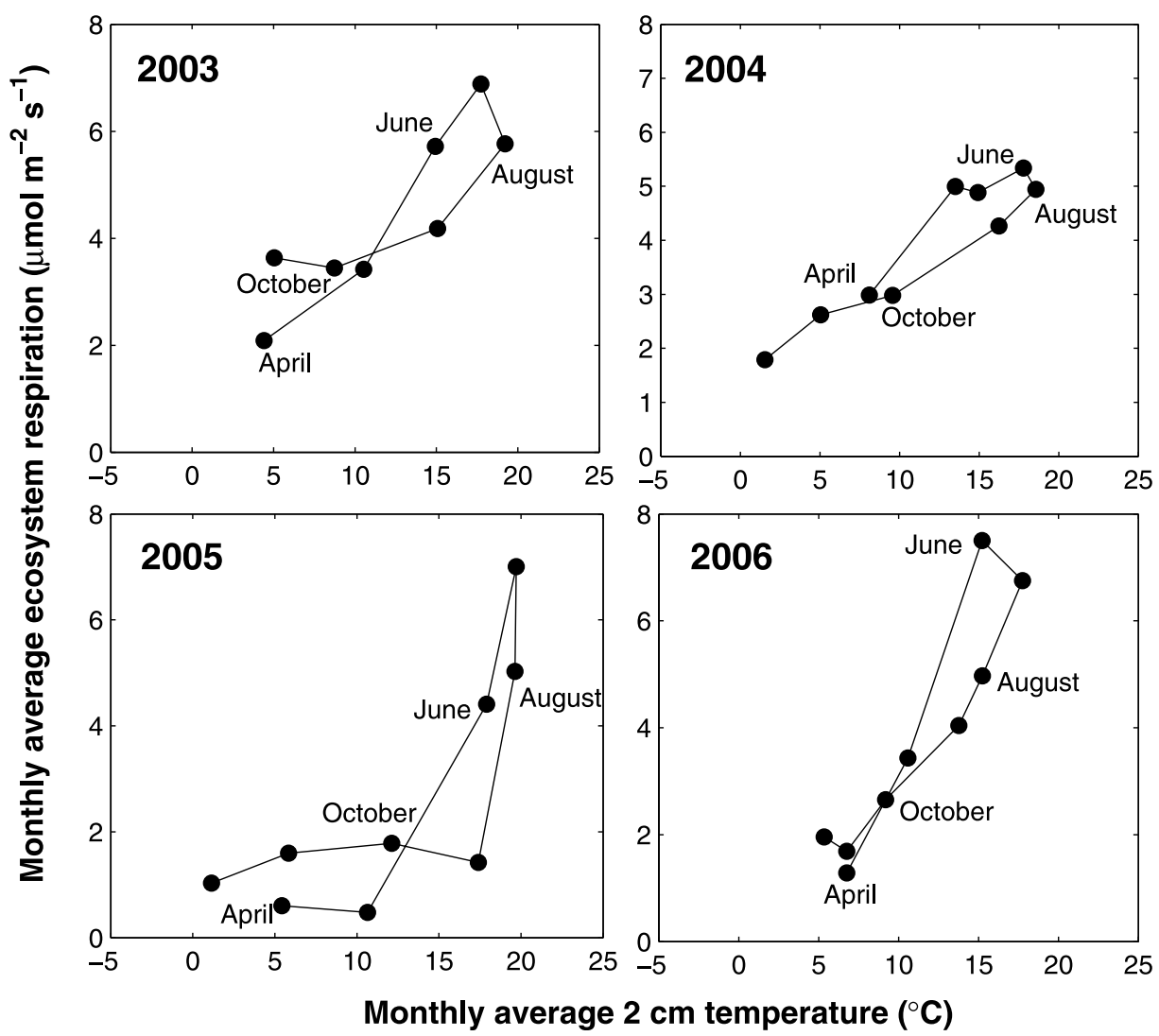

Figure 4. Monthly average $2 \mathrm{~cm}$ soil temperature versus monthly average gap-filled eddy covariance tower ER.

where $\beta_{o}$ is the slope and $\beta_{1}$ is the y intercept. The observed hysteresis decreased when available $5 \mathrm{~cm}$ and $16 \mathrm{~cm}$ soil temperatures from 2004 were used for plots with SR. Although SR did lag soil temperature by several hours, it appears that temperatures in the upper $5 \mathrm{~cm}$ may not be representative of the SR experienced by the majority of respiring soil. Hysteresis increased with SR during the summer months (Figure 8), was highly correlated with the range in SR values for a given day, and was not correlated with daily range of temperatures. Hysteresis decreased with increased soil moisture suggesting that increased soil moisture increases the heat capacity of the bulk soil reducing the temperature range (Figure 9). Other studies have found that the magnitude of the hysteresis is controlled by water limitation [Riveros-Iregui et al., 2007; Carbone et al., 2008].

[36] The magnitude of diel hysteresis of SR represents significant variation relative to the magnitude seasonal variation. The mean daily hysteresis magnitude in the upland in order of year was $2.94,4.51,4.78,4.86$, and $5.73 \mu \mathrm{mol} \mathrm{m}^{2} \mathrm{~s}^{-1}$ during the years 2003-2007. At the wetland margin these values were similar at $3.06,3.80,3.89,3.42$, and $4.25 \mu \mathrm{mol}$ $\mathrm{m}^{2} \mathrm{~s}^{-1}$, however the magnitude was less and 2006 did not fit in this increasing trend. As few flux measurements ever exceeded $10 \mu \mathrm{mol} \mathrm{m}^{2} \mathrm{~s}^{-1}$, these values are significant relative to the total seasonal variation. The magnitude of hysteresis increased 2003 to 2007, even as overall SR decreased. If the diel variation of SR is controlled by photosynthetic factors [Tang et al., 2005], the increase in SR hysteresis magnitude suggests that the soils were increasingly controlled by the rhizospheric component of soil $\mathrm{CO}_{2}$ production.

[37] The magnitude of diel hysteresis at Harvard Forest was within the same range reported by Liu et al. [2006], Vargas and Allen [2008], and Carbone et al. [2008] in forest and grassland ecosystems. Detailed comparisons of multiple sites in varying ecosystems and soil types may provide insight into the cause of this diel variability. Concurrent, high-resolution measurement of photosynthate transport and flux would provide a definitive link between aboveground photosynthetic processes and subsurface $\mathrm{CO}_{2}$ production. The link between photosynthesis and diel hysteresis [Tang et al., 2005] is speculative until a mechanistic understanding of the timing of downward photosynthate transport is attained [Liu et al., 2006; Vargas and Allen, 2008]. This nontemperature-related diel variation requires the use of daily averages for relating SR to environmental variables. The presence of the diel cycles supports the importance of automated SR measurements to avoid bias by manual measurements which are typically only collected during the daytime.

\subsection{Seasonal Patterns}

[38] In 2004, the only year of complete soil moisture data, there was no correlation between soil water content in any soil horizon and the magnitude of hysteresis. In any given year, precipitation patterns did not coincide with the seasonal pattern in SR. 

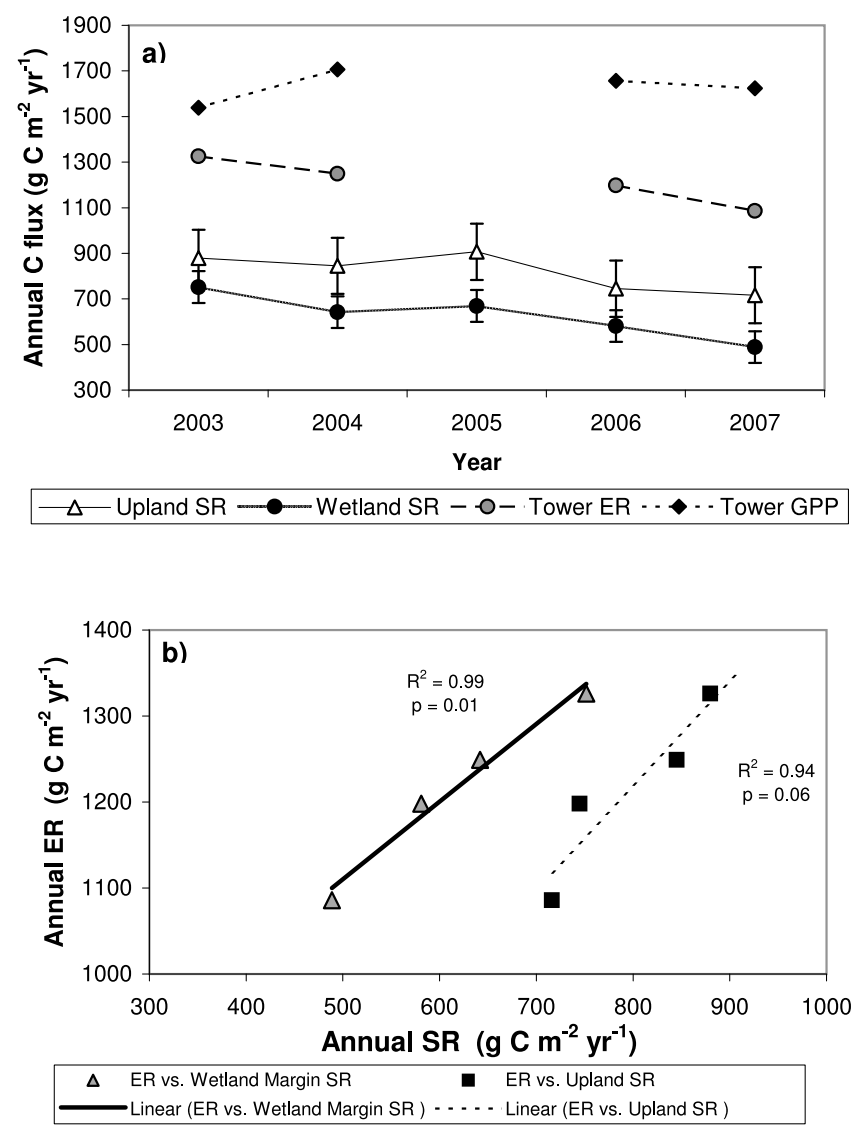

Figure 5. (a) Annual estimates of magnitudes of mean SR at upland and wetland margin chambers, tower ER, and tower GPP. Note that SR and ER are fluxes to the atmosphere, while GPP is a flux from the atmosphere. (b) Comparison of upland and wetland margin average SR with ER measured at the tower.

[39] Although there is a seasonal difference in soil temperature profiles (soils warm from the top down in the spring, and then cool from the top down in the fall), no correlation was found between temperature gradients in the soil and the hysteresis. SR investigations at more northerly temperate and boreal forests have emphasized the contribution of deep soil carbon decomposition in the late fall [Goulden et al., 1998] and late growing season [Risk et al., 2008]. Though we used a $2 \mathrm{~cm}$ temperature for plots of hysteresis, seasonal hysteresis was only slightly reduced when using the $5-7,16-18$, or $30 \mathrm{~cm}$ soil temperatures measured at the three soil profiles in 2004, or the $10 \mathrm{~cm}$ soil temperature measured at the site meteorological station in all years. The fact that the seasonal hysteresis does not disappear with deeper soil temperatures suggest that the seasonal hysteresis cannot be explained by lags in soil temperature alone.

[40] Seasonal variation in temperature sensitivity indicates that multiple confounding factors control the temperature sensitivity [Janssens and Pilegaard, 2003]. Changes in temperature sensitivity may be affected by vegetation phenology. Seasonal $\mathrm{Q}_{10}$ and basal SR estimates in a Belgian forest were demonstrated to be influenced by seasonal patterns in plant activity [Curiel Yuste et al., 2004] and modeled photosyn- thesis [Sampson et al., 2007]. One hypothesis is that root respiration and photosynthate transport to the roots varies on a seasonal scale, influencing SR but not synchronously with soil temperature. Since the availability of readily decomposed carbon substrate is a major factor affecting SR [Davidson et al., 2006c], an increase in exudation of carbohydrates from roots to the rhizosphere may increase SR. There is little information on the phenology of downward photosynthate transport or production of root exudates.

[41] Other studies have shown that photosynthesis has a strong effect on SR. A tree girdling experiment in Sweden revealed that cutting off the supply of photosynthate to the roots and mycorrhizal fungi reduced SR by $37 \%$ within 5 days [Högberg et al., 2001] and SR remained reduced during the following year [Bhupinderpal-Singh et al., 2003]. In an analysis of European flux tower data, GPP was determined to be the most significant factor in determining SR and ER, explained by the influence of photosynthate exudation and leaf litter and fine root production [Janssens et al., 2001]. Studies that have measured the contribution of root respiration to SR over the duration of a growing season in a Japanese forest [Lee et al., 2003] and a Tennessee forest [Cisneros Dozal et al., 2006] do not see significant variation in root respiration relative to SR. Various isotopic labeling studies have quantified a fast, vegetation-dependent link between photosynthesis and SR [Ekblad and Högberg, 2001; Carbone and Trumbore, 2007; Carbone et al., 2007]. At the Harvard Forest site, SR and GPP were not correlated on seasonal or interannual timescales.

[42] Litterfall also can have an impact on SR at Harvard Forest. Decomposition of newly fallen litter comprised $12 \%$ of total SR at the DIRT plots at Harvard Forest [Bowden et al., 1993]. However, the seasonal shift in our SR measurements began in July-August, much sooner than senescence. The increase in litterfall in autumn cannot fully explain the observed hysteresis.

[43] The seasonal hysteresis observed here has comparable direction to seasonal hysteresis of SR observed by Crill [1991], Goulden et al. [1998], Morén and Lindroth [2000], and Drewitt et al. [2002], and is opposite of the hysteresis reported by Gaumont-Guay et al. [2006a] and Vargas and Allen [2008]. The difference in hysteresis direction between sites and the difference in magnitudes of the hysteresis at this site suggest that vegetation type and soil structure have a strong effect on the nontemperature related seasonal variation in SR. Along with automated flux measurements, detailed observations of soil $\mathrm{CO}_{2}$ profiles, photosynthate transport, fine root/micorrhizal fungi growth, and heterotrophic microbial communities over the growing season are necessary to identify the sources of $\mathrm{CO}_{2}$ contributing to SR. Further work comparing the temperature-independent seasonal variation across various ecosystems could provide insight into additional controls on SR.

[44] SR residuals from annual temperature fits are sometimes correlated with soil moisture only on short timescales. Some individual rain events during mid to late summer produce an easily recognizable spike in the residual from a half-year temperature fit shortly after rain, which then subsides with soil moisture as the soil dries over a period of days. However, due to the large magnitude of nontemperature seasonal and diel variation, it is difficult to detect a consistent short-term effect of soil moisture on SR. Residuals from a 

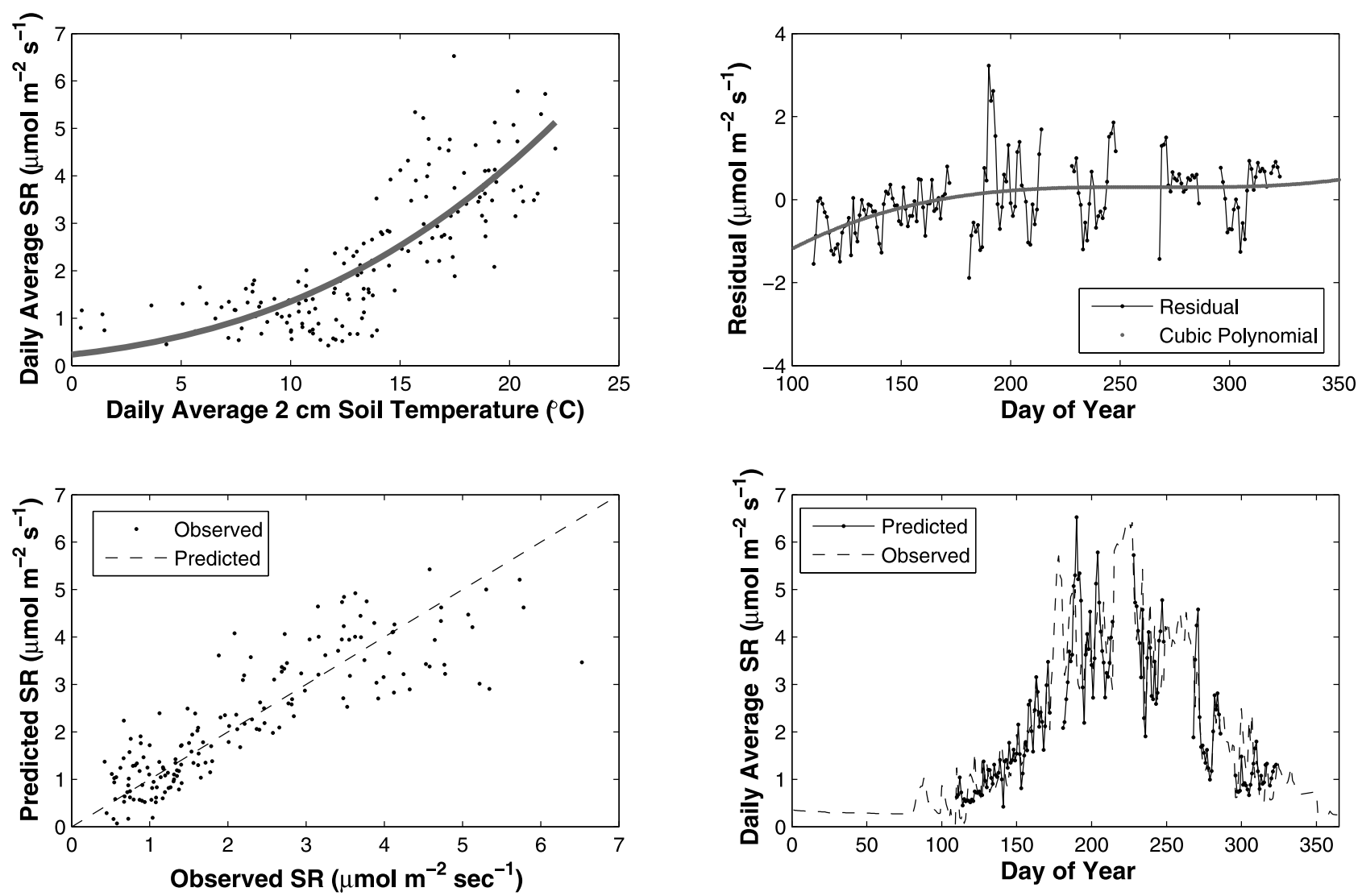

Figure 6. (top left) Steps and evaluation of modeling method: An Arrhenius regression fit of daily average $2 \mathrm{~cm}$ soil temperature and SR from chamber 5 in 2003. (top right) Residuals from exponential temperature regression with cubic polynomial fit. (bottom left) Observed daily averaged SR versus predicted daily SR and (bottom right) observed and predicted SR plotted as a daily time series.

temperature fit from an entire growing season or part of the growing season from these chambers could not be explained by soil water content, as others have done in forest ecosystems [Savage and Davidson, 2001; Borken et al., 2003; Savage and Davidson, 2003; Gaumont-Guay et al., 2006a]. Residuals from temperature regressions involving individual chambers and the aggregated upland and wetland margin sites did not show a quantifiable effect of soil moisture in relating instantaneous or daily averaged values. After modeling the seasonal variation in the residuals using a polynomial function, the fit or the residual to the polynomial did not correlate with soil moisture. This observation is likely due to a lack of

Table 3. Mean Absolute Error of Daily Averaged SR Compared to Modeled SR ${ }^{\mathrm{a}}$

\begin{tabular}{cccccc}
\hline & \multicolumn{5}{c}{ Mean Absolute Error } \\
\cline { 2 - 6 } Chamber & 2003 & 2004 & 2005 & 2006 & 2007 \\
\hline 1 & 0.39 & 0.38 & 0.48 & 0.42 & 0.40 \\
2 & 0.71 & 0.74 & 0.57 & 0.45 & 0.58 \\
3 & 0.56 & 0.58 & 0.67 & 0.68 & 0.55 \\
4 & 0.50 & 0.95 & 1.00 & 0.77 & 0.75 \\
5 & 0.55 & 0.69 & 0.80 & 0.48 & 0.74 \\
6 & 0.39 & 0.67 & 0.87 & 0.75 & 1.30 \\
7 & 0.51 & 0.54 & 0.81 & 0.53 & 0.61 \\
8 & 0.45 & 0.48 & 0.87 & 0.61 & 0.64 \\
\hline
\end{tabular}

${ }^{\mathrm{a}}$ Chambers $1-4$ are upland sites; chambers $5-8$ are wetland margin sites.

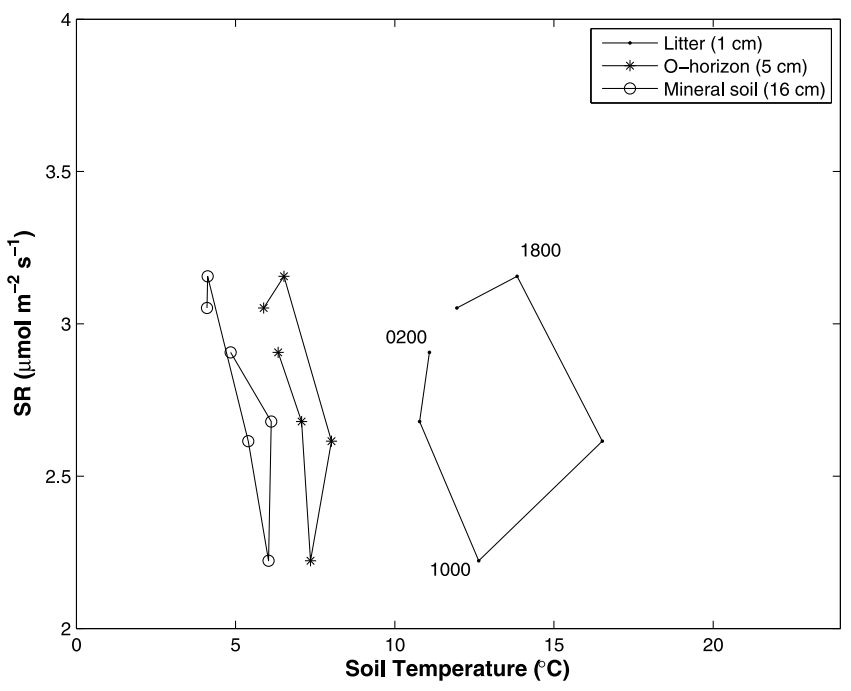

Figure 7. Example of diel hysteresis from chamber 2 (all of 2004). The $4 \mathrm{~h}$ average soil temperature $(2 \mathrm{~cm})$ versus $4 \mathrm{~h}$ average SR demonstrates a hysteresis in which SR is out of phase with soil temperature. Hour labels are included to demonstrate the direction of hysteresis loop (counterclockwise). Hysteresis decreases with deeper soil temperatures as a result of a lower temperature range. 

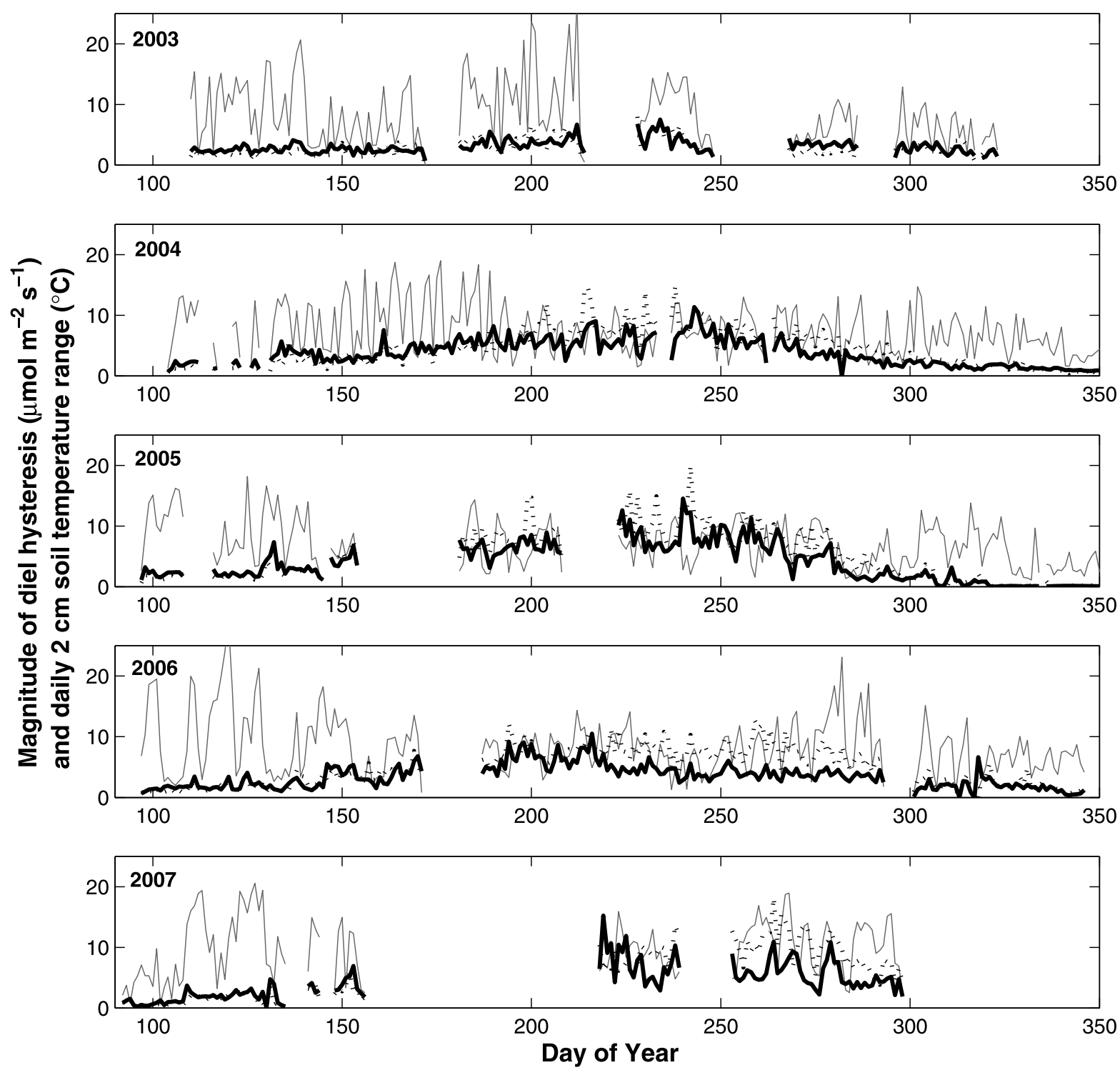

$2 \mathrm{~cm}$ temperature range $\ldots+\cdots$, Upland hysteresis magnitude

Wetland margin hysteresis magnitude

Figure 8. Time series of daily magnitude of hysteresis for upland and wetland margin SR plotted with the daily temperature range in all years. Magnitude of hysteresis is calculated from daily range of residuals to fit of SR to $2 \mathrm{~cm}$ soil temperature (see Figure 6 and text for details).

soil moisture data at suitable depths and the incorporation of soil moisture measured approximately $400 \mathrm{~m}$ away from the chambers.

[45] Comparing monthly averages of SR during July and August across years with similar soil temperatures and assumed same phenological state indicated that years with higher precipitation in the same month had higher SR. Residuals from linear regression of average temperature and SR during the same late summer months (August and September) were correlated with monthly precipitation anomalies (Figure 10).

\subsection{Annual Estimates of SR}

[46] Nonlinear temperature regressions of SR to $2 \mathrm{~cm}$ temperature provided a good estimate of annual $\mathrm{C}$ release. On annual scales these temperature relationships allowed for prediction of the overall annual pattern. Although the Arrhenius equation (equation (1)) was used to predict temperature response, it was used to derive an empirical relationship and not to predict instantaneous kinetics on which the equation is based. Due to seasonal and diel hysteresis, the temperature relationship to SR was inadequate for predicting short-term events. Fitting a cubic polynomial to the residuals of the temperature fit greatly improved the performance of the model.

[47] Our annual SR estimates were generally within a similar range or higher than those previously reported by manual measurements at Harvard Forest-760 and $870 \mathrm{~g} \mathrm{C} \mathrm{m}^{2} \mathrm{yr}^{-1}$ at upland sites and 370 and $410 \mathrm{~g} \mathrm{C} \mathrm{m}^{2} \mathrm{yr}^{-1}$ at wetland sites during 1996-1998 [Savage and Davidson, 2001]. Our wetland-margin SR values were higher than their reported wetland SR but lower than upland SR. Quantitative com- 

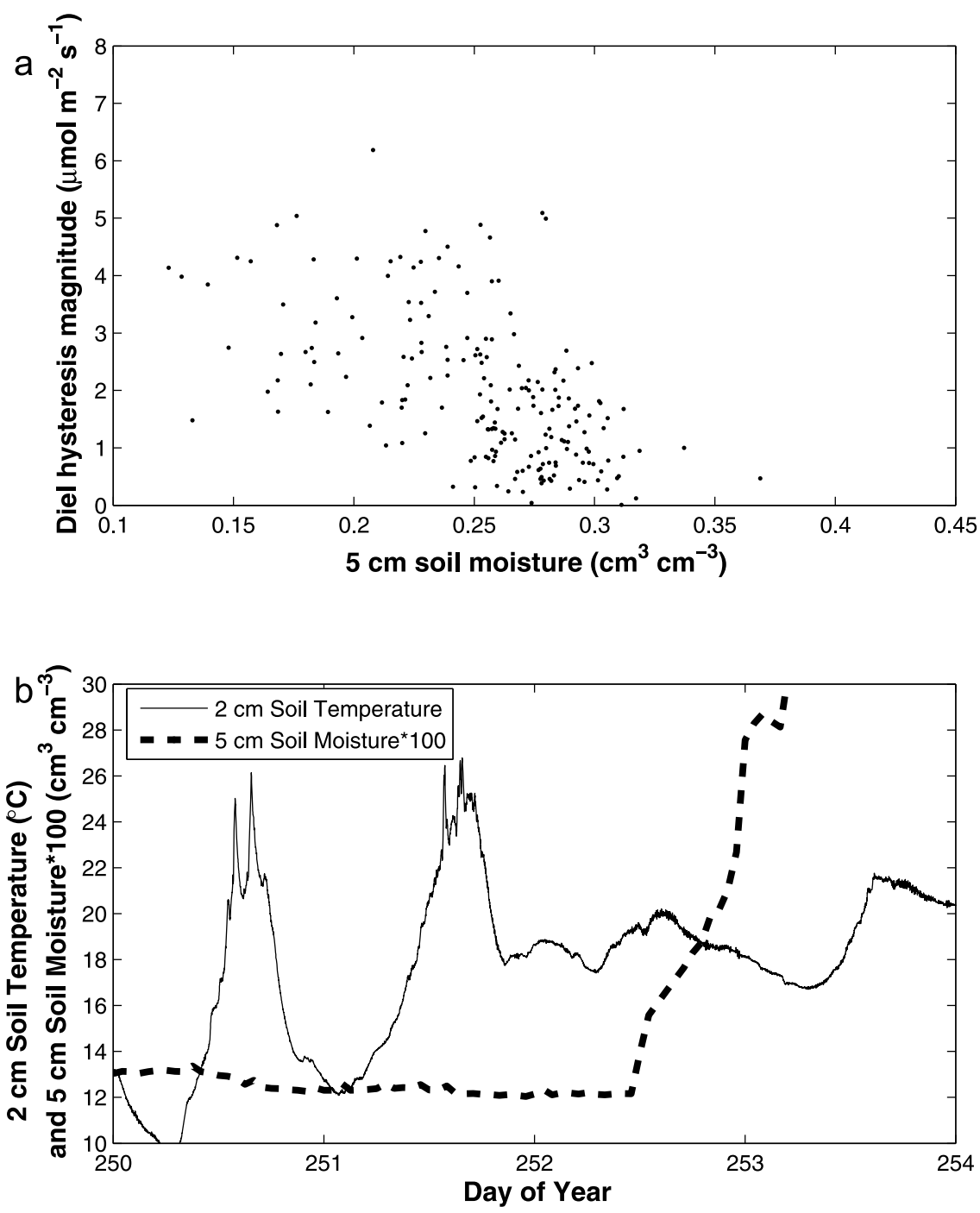

Figure 9. (a) Diel magnitude hysteresis from chamber 4 versus soil moisture. (b) Decrease in range of $2 \mathrm{~cm}$ soil temperatures during wetting event.

parisons of autochamber measurements with manual measurements will require intensive site-specific scaling and additional measurements to account for spatial and temporal advantages/limitations of each.

[48] The decrease in SR at this site occurs over a period in which the mean annual air temperature was increasing, though $2 \mathrm{~cm}$ soil temperature at the autochambers exhibited a decreasing trend over the 5 year measurement period (Figure 11). While the mean annual air temperatures over Harvard Forest generally increased 2003-2007, soil temperature under the canopy at the autochamber site decreased over the same time period (Figure 11). The inverse relationship between spring wetland margin and upland $2 \mathrm{~cm}$ soil temperatures and air temperatures at the meteorological station located in open field suggest phenology may modulate soil temperatures at the site by shading. Spring (AprilJune) night air temperatures increased $(\alpha=0.09)$ and spring day and night $2 \mathrm{~cm}$ soil temperatures decreased $(\alpha=0.14$ and $\alpha=0.14$ ) over 2003-2007. Fall (October and November) day air temperatures decreased $(\alpha=0.12)$ and fall day $2 \mathrm{~cm}$ soil temperatures increased $(\alpha=0.12)$ over the measurement period. Bud break in the three deciduous species present at the autochamber site occurs earlier during the years 2004-2006 compared to 2003 (Table 4). Regional warming at Harvard Forest may induce earlier leaf-out thus causing increased shading of the forest floor during the spring. Springtime (April-June) mean $2 \mathrm{~cm}$ soil temperatures are correlated with annual SR estimates for the wetland margin and upland (Figure 12a). Annual sums of SR are strongly correlated with July-September mean soil temperatures, but with opposite slopes for upland and wetland margin chambers, indicating a possible effect of soil moisture on fluxes (Figure 12b). Average October-November soil temperatures demonstrate little correlation with annual SR. Fall day air temperatures decreased significantly while fall day $2 \mathrm{~cm}$ temperatures increased significantly; however the fall phenology data does not suggest consistent changes in leaf color or leaf drop. Spring soil temperatures may be an important factor driving interannual variability of C release from soils. In 2004-2006 the decrease in daily temperature range at $2 \mathrm{~cm}$ was apparent as the soils became shaded (Figure 8). Annual soil tempera- 

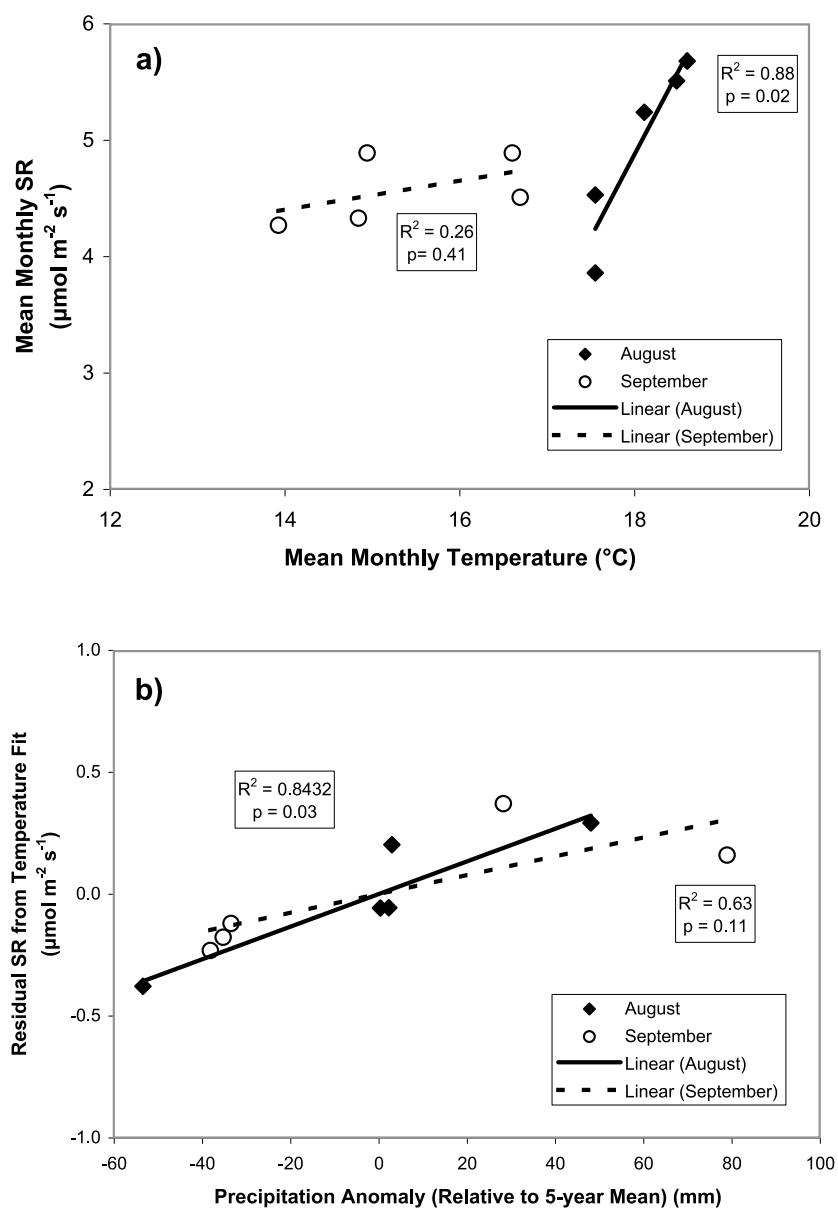

Figure 10. (a) August and September mean $2 \mathrm{~cm}$ soil temperature versus monthly mean SR for each year, and (b) residuals from these fits versus monthly precipitation anomalies relative to the 5 year mean 2003-2007. ture averages at the autochambers could not be used for analysis due to gaps in the data.

\subsection{Comparison to Tower Fluxes}

[49] The autochambers are located to the northwest of the HFEMS tower, in the direction of the prevailing winds. In each growing season, due to gaps in both data sets the number of instances in which the tower and autochambers measured a flux within the same hour was less than $20 \%$ of potential measurements. If the data were filtered by wind direction (northwest) to maximize the possibility of the chambers being within the tower's footprint, the amount of data available for comparison was reduced by another onethird. Insufficient data remained after filtering to make meaningful comparisons with near-instantaneous values. In addition, uncertainty in the tower's flux footprint raises questions as to whether the chambers are representative of the area actually measured by the tower. Diel hysteresis of SR also presents complications with relating instantaneous rates. However, because the two slope locations along the gradient and the wetland chambers capture the moisture range for soils in the footprint and there are a large number of measurements, chamber SR can be compared qualitatively to the gap-filled ER from the tower.

[50] Time series of both the ER and SR indicate that fluxes resulting from belowground processes occur on different seasonal patterns than fluxes from the combined above and belowground processes. The seasonal hysteresis of the tower is very different from that of SR. ER reaches a maximum earlier in the summer (May-June) than SR, which peaks later in the summer (July-August). This is consistent with the notion that the vegetation and soil have very different seasonal patterns. Foliar activity during budbreak and leaf expansion peaks early in the growing season before the soils warm. Late in the growing season carbon substrate from trees is transferred to the still warm soils during senescence. The differences in hysteresis of ER and SR are consistent with the time series of these measurements, as

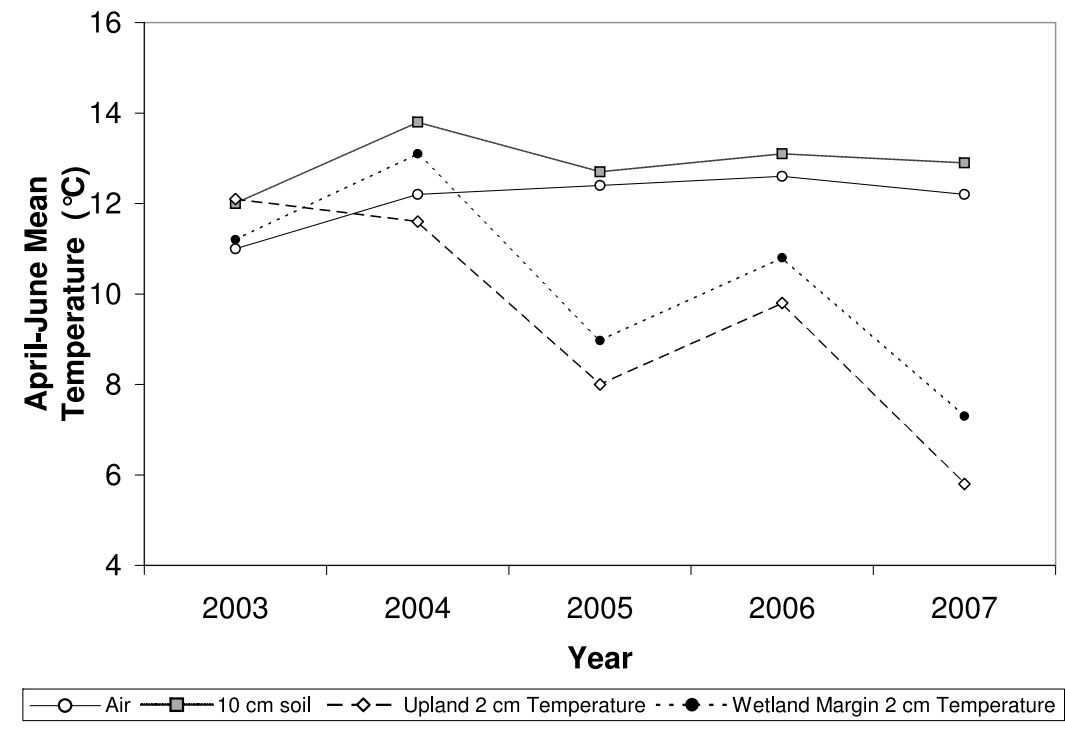

Figure 11. Mean annual air and $10 \mathrm{~cm}$ soil temperature measured at the Harvard Forest meteorological station (open field) and autochamber sites (under canopy). 

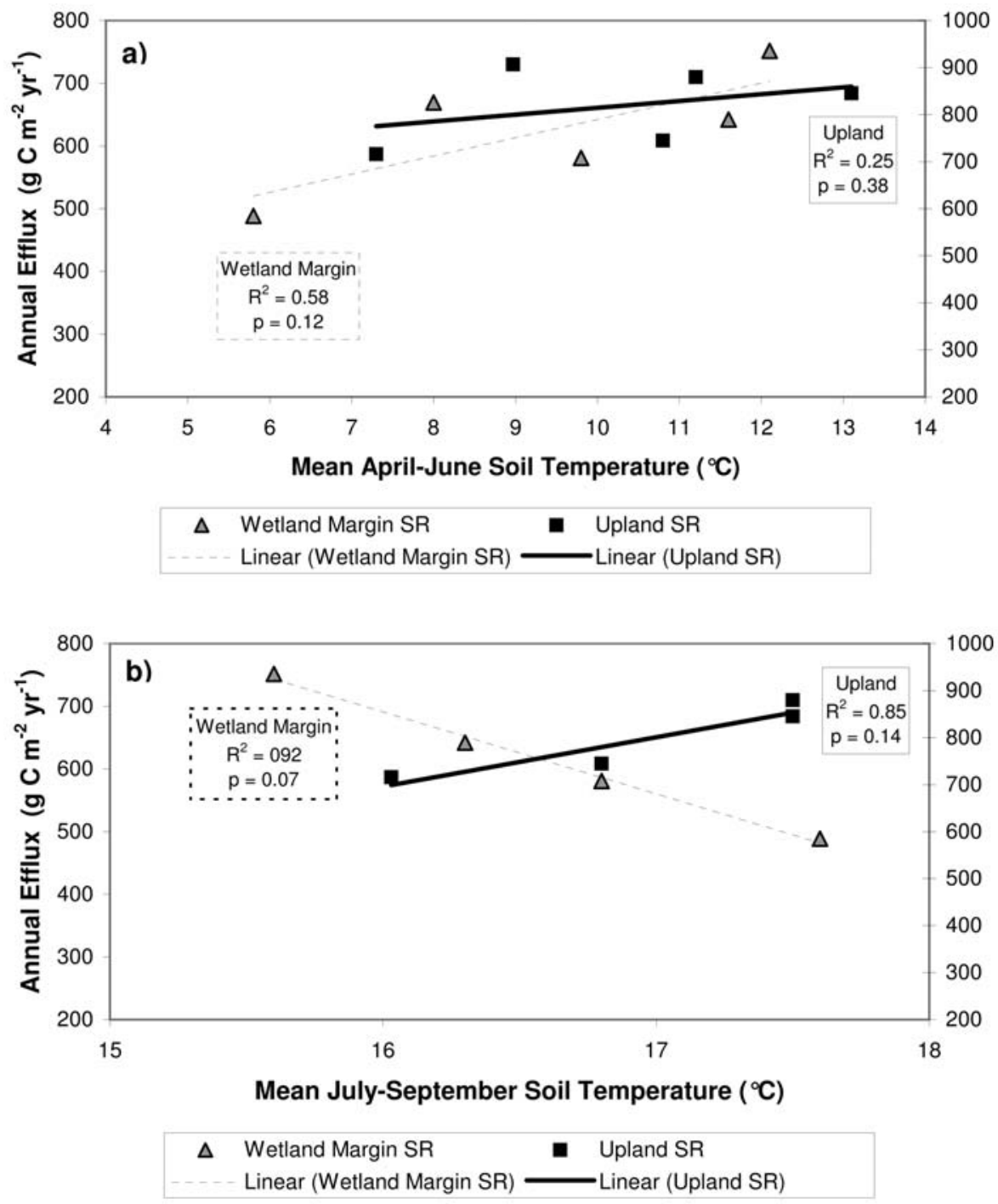

Figure 12. Scatterplots of annual SR versus mean seasonal $2 \mathrm{~cm}$ soil temperatures from (a) April-June and (b) July-September.

well as the seasonal pattern observed in Howland Forest by Davidson et al. [2006a]. Early in the spring SR approached ER when the soils were warmed by the sun before foliage shades the forest floor. Mean springtime aboveground respiration, estimated by subtraction of upland SR from ER, was $0.7,0.8,2.1$, and $4.2 \mu \mathrm{mol} \mathrm{m}^{2} \mathrm{~s}^{-1}$ in 2003, 2004, 2006, and 2007. Springtime SR decreased over this period while ER increased.

[51] In principle, SR is only one component of the ecosystem flux and cannot exceed ER. Other studies have encountered chamber-based SR measurements that exceed ER measured by EC but the exact cause is unknown [Griffis et al., 2003]. Because our upland SR measurements were sometimes larger than the flux tower ER, it raises questions about the distribution of site types in the tower footprint. To the extent that areas of lower fluxes, such as the wetland, or areas of no flux, such as rock outcroppings or tree basal area, preferentially dominate the tower footprint relative to the autochambers, the tower will measure lower fluxes than some of the chambers measuring on soils with higher $\mathrm{CO}_{2}$ flux.

[52] If some of the soil-respired $\mathrm{CO}_{2}$ is advected away from the tower and escapes above the canopy at another location, the tower may miss these vertical fluxes [Goulden et al., 1996b; Baldocchi et al., 2000]. Horizontal advection of $\mathrm{CO}_{2}$ accounts for a significant component of forest $\mathrm{CO}_{2}$ transport [Feigenwinter et al., 2004], especially on sloping terrain [Lee, 1998; Aubinet et al., 2003]. Even shallowly sloping terrain can result in significant advection and underestimation of ER [Lee, 1998]. Significant preferential venting of $\mathrm{CO}_{2}$ has been observed at a Wisconsin forest [Cook et al., 2004]. At Harvard Forest, horizontal advection of $\mathrm{CO}_{2}$ is prevalent in calm conditions, and accounting for this term can improve calculations of nighttime NEE [Staebler and Fitzjarrald, 2004]. However, gap filling of NEE at the HFEMS is based on excluding calm periods, reducing the influence of advective losses.

[53] Long-term bias in both SR and ER measurements cannot be ruled out as a possible cause of the mismatch. 
Table 4. Spring and Fall Phenology for Three Deciduous Species at the Autochamber Site ${ }^{a}$

\begin{tabular}{|c|c|c|c|c|c|c|c|c|}
\hline & \multicolumn{4}{|c|}{ Spring Phenology (Day of Year) } & \multicolumn{4}{|c|}{ Fall Phenology (Day of Year) } \\
\hline & $\begin{array}{l}\text { First Bud } \\
\text { Break }\end{array}$ & $\begin{array}{l}\text { All Bud } \\
\text { Break }\end{array}$ & $\begin{array}{l}\text { First Measurable } \\
\text { Leaf Growth }\end{array}$ & $\begin{array}{l}90 \% \text { Leaf } \\
\text { Growth }\end{array}$ & $\begin{array}{l}\text { First Leaf } \\
\text { Color }\end{array}$ & $\begin{array}{c}\text { First Leaf } \\
\text { Drop }\end{array}$ & $\begin{array}{l}100 \% \text { Leaf } \\
\text { Color }\end{array}$ & $\begin{array}{l}100 \% \text { Leaf } \\
\text { Fall }\end{array}$ \\
\hline \multicolumn{9}{|l|}{ Acer rubrum } \\
\hline 2003 & 128 & 151 & 143 & 166 & 252 & 259 & 288 & 295 \\
\hline 2004 & 123 & 139 & 132 & 159 & 248 & 257 & 285 & 291 \\
\hline 2005 & 125 & 137 & 138 & 161 & 247 & 254 & 293 & 303 \\
\hline 2006 & 124 & 141 & 136 & 165 & 249 & 254 & 281 & 287 \\
\hline \multicolumn{9}{|l|}{ Quercus rubrum } \\
\hline 2003 & 135 & 147 & 145 & 171 & 259 & 276 & 301 & 311 \\
\hline 2004 & 124 & 134 & 132 & 161 & 260 & 278 & 303 & 313 \\
\hline 2005 & 125 & 139 & 139 & 170 & 259 & 281 & 311 & 319 \\
\hline 2006 & 127 & 140 & 138 & 167 & 255 & 270 & 304 & 315 \\
\hline \multicolumn{9}{|l|}{ Quercus alba } \\
\hline 2003 & 138 & 161 & 151 & 174 & 250 & 264 & 299 & 308 \\
\hline 2004 & 132 & 142 & 138 & 167 & 262 & 264 & 295 & 315 \\
\hline 2005 & 136 & 159 & 149 & 176 & 259 & 270 & 301 & 316 \\
\hline 2006 & 132 & 149 & 144 & 170 & 260 & 272 & 287 & 308 \\
\hline \multicolumn{9}{|c|}{ Average annual change ${ }^{b}$} \\
\hline Acer rubrum & -1.4 & -3.3 & -2.3 & -0.3 & -0.9 & -1.6 & -2.1 & -2.7 \\
\hline Quercus rubrum & -2.1 & -4.0 & -2.4 & -1.3 & -1.3 & -2.2 & 0.8 & 1.6 \\
\hline Quercus alba & -2.7 & -2.4 & -2.3 & -1.3 & 3.4 & 2.8 & -3.9 & 0.0 \\
\hline
\end{tabular}

a Data source: J. O’Keefe.

${ }^{\mathrm{b}}$ From 2003 to 2006 (days).

Errors associated with EC measurements may cause an underestimation in ER, and recent work suggests that closed chamber measurements may overestimate SR during periods of low-turbulence conditions [Schneider et al., 2009]. The combination of these effects was not readily deciphered in the data, but cannot be eliminated as possible issues.

[54] On annual scales, SR was consistently lower than ER (Figure 6). Although short-term comparisons revealed occurrences of SR exceeding ER, annual estimates of SR were consistently below $60 \%$ of ER. ER decreased over the period 2003 to 2006 and was strongly correlated with SR (Figure 6). SR is a strong predictor of ER and comprises a significant fraction of the total efflux. Wetland margin annual $\mathrm{C}$ release was $56 \%, 54 \%, 48 \%$, and $40 \%$ of total $\mathrm{C}$ emission (ER) measured by the tower in 2003, 2004, 2006, and 2007, respectively. Upland $\mathrm{C}$ release over the same period was $57 \%, 59 \%, 48 \%$, and $42 \%$. Chamber measurements of SR across an assortment of temperate and boreal forest sites typically comprise a large seasonally varying fraction (45-94\%) of tower ER in temperate and boreal forests [Lavigne et al., 1997; Law et al., 1999; Curiel Yuste et al., 2005; Davidson et al., 2006a; Gaumont-Guay et al., 2006b; Ohkubo et al., 2007; Zha et al., 2007]. The values from Harvard Forest fall toward the low end of this range. These ratios are consistent with the $0.68 \mathrm{SR} / \mathrm{ER}$ ratio at Harvard Forest reported by Goulden et al. [1996a] based on measurements from June to September 1992 (the months bracketing the period with the largest SR/ER ratio between 2003 and 2007).

[55] The decreasing ratios of annual SR/ER across 2003 to 2007 indicate that the SR component of total ER was declining. Increased and earlier foliar expansion may have been driving decreased SR by cooling soils, while increasing aboveground respiration. Springtime daily temperatures ranges increase before leaf-out and then stabilize [Schwartz, 1996] influencing the heat and water balance of the forest [Fitzjarrald et al., 2001]. Earlier leaf expansion as a result of increased springtime temperatures drives a negative feed- back on warming due to longer periods of $\mathrm{CO}_{2}$ uptake and evapotranspiration [Peñuelas et al., 2009]. The annual patterns of SR and temperature observed here suggest an additional feedback on climate caused by an extended season of leaf cover.

\section{Conclusions}

[56] Four years of high-frequency autochamber measurements of SR at adjacent upland and wetland margin sites at Harvard Forest revealed large interannual and seasonal variability. SR rates were higher at the upland chambers than the wetland margin in all years; differences were most apparent in the late summer and early fall. A pronounced seasonal hysteresis was observed in all years and varied interannually. Microbial contribution to SR may change from free heterotrophs to the rhizosphere later in the growing season. A significant diel hysteresis was also observed, with SR lower in midmorning than late afternoon at similar soil temperatures. The seasonal and diel hysteresis emphasizes the importance of automated measurements and potential problems with using seasonal or annual temperature relationships to predict short-term SR rates based on temperatures.

[57] Annual estimates of SR decreased from 2003 to 2007 and were strongly correlated with ER during the same time period. Annual sums of SR were correlated with mean spring soil temperatures. Mean spring soil temperatures decreased over the measurement period while air temperatures increased over the same period. Earlier foliar expansion as a result of warming may be the cause of the soil surface cooling via earlier increased shading. The synchronous decrease in spring soil temperatures and SR during regional warming of air temperatures may represent a negative feedback on a warming climate by reducing $\mathrm{CO}_{2}$ production from soils.

[58] Variations in temperature and soil moisture fail to explain all of the variability in SR. Soil moisture had a notable impact on transients in SR following precipitation, but the combined effects of temperature and moisture could 
not be disentangled on a growing-season timescale to determine their individual contributions to controlling SR. However, the seasonality of SR and its relationship to total ER suggest that different phenology of root/rhizosphere respiration and free soil microbes are critical to understanding the annual variability of SR. Aboveground respiration by emerging foliage contributes to a spring/early summer maximum in ER while $\mathrm{SR}$ is at a maximum and contributes most to ER in late summer due to rhizosphere activity. In the future, more detailed observations of vegetation metabolism and photosynthate transport besides temperature and soil moisture will need to be included with observations of SR to better understand the processes that control SR. The larger magnitude of SR compared ER in certain times of the year demonstrates the need for a comprehensive footprint model to independently evaluate SR and ER.

[59] Annual comparisons of SR to ER show SR contributed $40-57 \%$ of total ER. The annual SR/ER ratio decreased from 2003 to 2007 suggesting that the decrease in ER is driven primarily by decreases in SR, and aboveground respiration did not decrease with the same trend. The decline in SR and ER over a 5 year period after a decade of increasing ER implies that decadal variation in temperate forest ecosystems is significant and partially driven by changes in SR.

[60] Acknowledgments. The authors would like to thank the personnel at the Harvard Forest and Pieter Beckman, Jess Alexander, Andrew Mosedale, and Bianca Moebius, and the UNH-EOS machine shop for building and maintaining the autochamber system. Phenology of woody species data were provided by John O'Keefe through the Harvard Forest data archive. This project was supported by the U.S. Department of Energy's Office (BER) through the Northeastern Regional Center of the National Institute for Global Environmental Change (123246-15), and the Northeastern Regional Center of the National Institute for Climate Change Research (3219UNHUSDOE4157), and NASA (NNG04GH75G and NNX07AH32G). Tower flux observations were supported by the Office of Science (BER), U.S. Department of Energy grant DE-FG0207ER64358, and through the Northeastern Regional Center of the National Institute for Climate Change Research (3452-HU-DOE-4157).

\section{References}

Aubinet, M., B. Heinesch, and M. Yernaux (2003), Horizontal and vertical $\mathrm{CO}_{2}$ advection in a sloping forest, Boundary Layer Meteorol., 108, $397-$ 417, doi:10.1023/A:1024168428135.

Bain, W. G., L. Hutyra, D. C. Patterson, A. V. Bright, B. C. Daube, J. W. Munger, and S. C. Wofsy (2005), Wind-induced error in the measurement of soil respiration using closed dynamic chambers, Agric. For. Meteorol., 131, 225-232, doi:10.1016/j.agrformet.2005.06.004.

Baldocchi, D. D., C. A. Vogel, and B. Hall (1997), Seasonal variation of carbon dioxide exchange rates above and below a boreal jack pine forest, Agric. For. Meteorol., 83, 147-170, doi:10.1016/S0168-1923(96)02335-0.

Baldocchi, D., J. Finnigan, K. Wilson, K. T. Paw U, and E. Falge (2000), On measuring net ecosystem carbon exchange over tall vegetation and complex terrain, Boundary Layer Meteorol., 96, 257-291, doi:10.1023/ A:1002497616547.

Barford, C. C., S. C. Wofsy, M. L. Goulden, J. W. Munger, E. H. Pyle, S. P. Urbanski, L. Hutyra, S. R. Saleska, D. Fitzjarrald, and K. Moore (2001), Factors controlling long- and short-term sequestration of atmospheric $\mathrm{CO}_{2}$ in a mid-latitude forest, Science, 294, 1688-1691, doi:10.1126/science. 1062962 .

Bhupinderpal-Singh, A. Nordgren, M. Ottosson-Löfvenius, M. N. Högberg, P.-E. Mellander, and P. Högberg (2003), Tree root and soil heterotrophic respiration as revealed by girdling of boreal Scots pine forest: Extending observations beyond the first year, Plant Cell Environ., 26, 1287-1296, doi:10.1046/j.1365-3040.2003.01053.x.

Black, T. A., W. J. Chen, A. G. Barr, M. A. Arain, Z. Chen, Z. Nesic, E. H. Hogg, H. H. Neumann, and P. C. Yang (2000), Increased carbon sequestration by a boreal deciduous forest in years with a warm spring, Geophys. Res. Lett., 27, 1271-1274, doi:10.1029/1999GL011234.
Boone, R. D., K. J. Nadelhoffer, J. D. Canary, and J. P. Kaye (1998), Roots exert a strong influence on the temperature sensitivity of soil respiration, Nature, 396, 570-572, doi:10.1038/25119.

Borken, W., E. A. Davidson, K. Savage, J. Gaudinski, and S. E. Trumbore (2003), Drying and wetting effects on carbon dioxide release from organic horizons, Soil Sci. Soc. Am. J., 67, 1888-1896.

Borken, W., K. Savage, E. A. Davidson, and S. E. Trumbore (2006), Effects of experimental drought on soil respiration and radiocarbon efflux from a temperate forest soil, Global Change Biol., 12, 177-193, doi:10.1111/j.1365-2486.2005.001058.x.

Bowden, R. D., K. J. Nadelhoffer, R. D. Boone, J. M. Mellilo, and J. B. Garrison (1993), Contributions of above ground litter, belowground litter, and root respiration to total soil respiration in a temperate mixed hardwood forest, Can. J. For. Res., 23, 1402-1407, doi:10.1139/x93-177.

Bubier, J., P. Crill, A. Mosedale, S. Frolking, and E. Linder (2003), Peatland responses to varying interannual moisture conditions as measured by automatic $\mathrm{CO}_{2}$ chambers, Global Biogeochem. Cycles, 17(2), 1066, doi:10.1029/2002GB001946.

Burrows, E. H., J. L. Bubier, A. Mosedale, G. W. Cobb, and P. M. Crill (2005), Net ecosystem exchange of carbon dioxide in a temperate poor fen: A comparison of automated and manual chamber techniques, Biogeochemistry, 76, 21-45, doi:10.1007/s10533-004-6334-6.

Burton, A. J., K. S. Pregitzer, G. P. Zogg, and D. R. Zak (1998), Drought reduces root respiration in sugar maple forests, Ecol. Appl., 8, 771-778, doi:10.1890/1051-0761(1998)008[0771:DRRRIS]2.0.CO;2.

Carbone, M. S., and S. E. Trumbore (2007), Contribution of new photosynthetic assimilates to respiration by perennial grasses and shrubs: Residence times and allocation patterns, New Phytol., 176, 124-135, doi:10.1111/j.1469-8137.2007.02153.x.

Carbone, M. S., C. I. Czimzcik, K. E. McDuffee, and S. E. Trumbore (2007), Allocation and residence time of photosynthetic products in a boreal forest using a low-level ${ }^{14} \mathrm{C}$ pulse-chase labeling technique, Global Change Biol., 13, 466-477, doi:10.1111/j.1365-2486.2006.01300.x.

Carbone, M. S., G. C. Winston, and S. E. Trumbore (2008), Soil respiration in perennial grass and shrub ecosystems: Linking environmental controls with plant and microbial sources on seasonal and diel timescales, J. Geophys. Res., 113, G02022, doi:10.1029/2007JG000611.

Carrara, A., A. S. Kowalski, J. Neirynck, I. A. Janssens, J. Curiel Yuste, and R. Ceulemans (2003), Net ecosystem $\mathrm{CO}_{2}$ exchange of mixed forest in Belgium over 5 years, Agric. For. Meteorol., 119, 209-227, doi:10.1016/S0168-1923(03)00120-5

Cisneros-Dozal, L. M., S. Trumbore, and P. J. Hanson (2006), Partitioning sources of soil-respired $\mathrm{CO}_{2}$ and their seasonal variation using a unique radiocarbon tracer, Global Change Biol., 12, 194-204, doi:10.1111/ j.1365-2486.2005.001061.x.

Cook, B. D., et al. (2004), Carbon exchange and venting anomalies in an upland deciduous forest in northern Wisconsin, USA, Agric. For. Meteorol., 126, 271-295, doi:10.1016/j.agrformet.2004.06.008.

Crill, P. M. (1991), Seasonal patterns of methane uptake and carbon dioxide release by a temperate woodland soil, Global Biogeochem. Cycles, 5, 319334, doi:10.1029/91GB02466.

Crill, P. M., M. Keller, A. Weitz, B. Grauel, and E. Veldkamp (2000), Intensive field measurements of nitrous oxide emissions from a tropical agricultural soil, Global Biogeochem. Cycles, 14, 86-96, doi:10.1029/ 1999GB900088.

Curiel Yuste, J., I. A. Janssens, A. Carrara, and R. Cuelemans (2004), Annual $\mathrm{Q}_{10}$ of soil respiration reflects plant phenological patterns as well as temperature sensitivity, Global Change Biol., 10, 161-169, doi:10.1111/j.1529-8817.2003.00727.x.

Curiel Yuste, J., M. Nagy, I. A. Janssens, A. Carrara, and R. Cuelemans (2005), Soil respiration in a mixed temperate forest and its contribution to total ecosystem respiration, Tree Physiol., 25, 609-619.

Curtis, P. S., P. J. Hanson, P. Bolstad, C. Barford, J. C. Randolph, H. P. Schmid, and K. B. Wilson (2002), Biometric and eddy-covariance based estimates of annual carbon storage in five eastern North American deciduous forests, Agric. For. Meteorol., 113, 3-19, doi:10.1016/S0168-1923 (02)00099-0.

Davidson, E. A., and I. A. Janssens (2006), Temperature sensitivity of soil carbon decomposition and feedbacks to climate change, Nature, 440 165-173, doi:10.1038/nature04514.

Davidson, E. A., S. E. Trumbore, and R. Amundsen (2000), Soil warming and organic carbon content, Nature, 408, 789-790, doi:10.1038 35048672

Davidson, E. A., K. Savage, L. V. Verchot, and R. Navarro (2002), Minimizing artifacts and biases in chamber-based measurements of soil respiration, Agric. For. Meteorol., 113, 21-37, doi:10.1016/S0168-1923(02) 00100-4.

Davidson, E. A., A. D. Richardson, K. E. Savage, and D. Y. Hollinger (2006a), A distinct pattern of the ratio of soil respiration to total ecosys- 
tem respiration in a spruce-dominated forest, Global Change Biol., 12, 230-239, doi:10.1111/j.1365-2486.2005.01062.x.

Davidson, E. A., K. E. Savage, S. E. Trumbore, and W. Borken (2006b), Vertical partitioning of $\mathrm{CO}_{2}$ production within a forest soil, Global Change Biol., 12, 944-956, doi:10.1111/j.1365-2486.2005.01142.x.

Davidson, E. A., I. A. Janssens, and Y. Luo (2006c), On the variability of respiration in terrestrial ecosystems: Moving beyond $\mathrm{Q}_{10}$, Global Change Biol., 12, 154-164, doi:10.1111/j.1365-2486.2005.01065.x.

Desai, A. R., et al. (2008), Influence of vegetation and seasonal forcing on carbon dioxide fluxes across the Upper Midwest, USA: Implications for regional scaling, Agric. For. Meteorol., 148, 288-308, doi:10.1016/ j.agrformet.2007.08.001

Drewitt, G. B., T. A. Black, Z. Nesic, E. R. Humphreys, E. M. Jork, R. Swanson, G. J. Ethier, T. Griffis, and K. Morgentern (2002), Measuring forest floor $\mathrm{CO}_{2}$ fluxes in a Douglas-fir forest, Agric. For Meteorol., 110, 299-317, doi:10.1016/S0168-1923(01)00294-5.

Efron, B., and R. Tibshirani (1986), Bootstap methods for standard errors, confidence intervals, and other measures of statistical accuracy, Stat. Sci., 1 , 54-75, doi:10.1214/ss/1177013815.

Ehman, J. L., H. P. Schmid, C. S. B. Grimmond, J. C. Randolph, P. J. Hanson, C. A. Wayson, and F. D. Cropley (2002), An initial comparison of micrometeorological and ecological inventory estimates of carbon exchange in a mid-latitude deciduous forest, Global Change Biol., 8 , 575-589, doi:10.1046/j.1365-2486.2002.00492.x.

Ekblad, A., and P. Högberg (2001), Natural abundance of ${ }^{13} \mathrm{C}$ in $\mathrm{CO}_{2}$ respired from forest soils reveal the speed of link between tree photosynthesis and root respiration, Oecologia, 127, 305-308, doi:10.1007/ s004420100667.

Feigenwinter, C., C. Bernhofer, and R. Vogt (2004), The influence of advection on the short-term $\mathrm{CO}_{2}$ budget in and above a forest canopy, Boundary Layer Meteorol., 113, 201-224, doi:10.1023/B: BOUN.0000039372.86053.ff.

Fitzjarrald, D., O. C. Acevedo, and K. E. Moore (2001), Climatic consequences of leaf presence in the eastern United States, J. Clim., 14 598-614, doi:10.1175/1520-0442(2001)014<0598:CCOLPI $>2.0 . \mathrm{CO} ; 2$.

Foster, D. (1992), Land-use history (1730-1990) and vegetation dynamics in central New England, J. Ecol., 80, 753-772, doi:10.2307/2260864.

Gaumont-Guay, D., T. A. Black, T. J. Griffis, A. G. Barr, R. S. Jassal, and $Z$. Nesic (2006a), Interpreting the dependence of soil respiration on soil temperature and water content in a boreal aspen stand, Agric. For. Meteorol., 140, 220-235, doi:10.1016/j.agrformet.2006.08.003.

Gaumont-Guay, D., T. A. Black, T. J. Griffis, A. G. Barr, K. Morgenstern, R. S. Jassal, and Z. Nesic (2006b), Influence of temperature and drought on seasonal and interannual variations of soil, bole, and ecosystem respiration in a boreal aspen stand, Agric. For. Meteorol., 140, 203-219, doi:10.1016/j.agrformet.2006.08.002.

Goulden, M. L., and P. M. Crill (1997), Automated measurements of CO exchange at the moss surface of a black spruce forest, Tree Physiol., 17 , 537-542.

Goulden, M. L., J. W. Munger, S.-M. Fan, B. C. Daube, and S. C. Wofsy (1996a), Measurements of carbon sequestration by long-term eddy covariance: Methods and a critical evaluation of accuracy, Global Change Biol., 2, 169-182, doi:10.1111/j.1365-2486.1996.tb00070.x.

Goulden, M. L., J. W. Munger, S.-M. Fan, B. C. Daube, and S. C. Wofsy (1996b), Exchange of carbon dioxide by a deciduous forest: Response to interannual climate variability, Science, 271, 1576-1578, doi:10.1126/ science. 271.5255 .1576

Goulden, M. L., et al. (1998), Sensitivity of boreal forest carbon balance to soil thaw, Science, 279, 214-217, doi:10.1126/science.279.5348.214.

Griffis, T. J., T. A. Black, K. Morgenstern, A. G. Barr, Z. Nesic, G. B. Drewitt, D. Guamont-Guay, and J. H. McCaughey (2003), Ecophysiological controls on the carbon balances of three southern boreal forests, Agric. For. Meteorol., 117, 53-71, doi:10.1016/S0168-1923(03)00023-6.

Hanson, P. J., N. T. Edwards, C. T. Garten, and J. A. Andrews (2000), Separating root and soil microbial contributions to soil respiration: A review of methods and observations, Biogeochemistry, 48, 115-146, doi:10.1023/A:1006244819642.

Hibbard, K. A., B. E. Law, M. Reichstein, and J. Sulzman (2005), An analysis of soil respiration across northern hemisphere ecosystems, Biogeochemistry, 73, 29-70, doi:10.1007/s10533-004-2946-0.

Hirano, T., H. Kim, and Y. Tanaka (2003), Long-term half-hourly measurement of soil $\mathrm{CO}_{2}$ concentration and soil respiration in a temperate deciduous forest, J. Geophys. Res., 108(D20), 4631, doi:10.1029/ 2003JD003766.

Hirsch, A. I., S. E. Trumbore, and M. L. Goulden (2002), Direct measurement of the deep soil respiration accompanying seasonal thawing of a boreal forest soil, J. Geophys. Res., 107, 8221, doi:10.1029/ 2001JD000921 [printed 108(D23), 2003].
Högberg, P., A. Nordgren, N. Buchman, A. F. S. Taylor, A. Ekbald, M. N. Högberg, G. Nyberg, M. Ottoson-Löfvenius, and D. J. Read (2001), Large-scale forest girdling shows that current photosynthesis drives soil respiration, Nature, 411, 789-792, doi:10.1038/35081058.

Janssens, I. A., and K. Pilegaard (2003), Large seasonal changes in $\mathrm{Q}_{10}$ of soil respiration in a beech forest, Global Change Biol., 9, 911-918, doi:10.1046/j.1365-2486.2003.00636.x

Janssens, I. A., et al. (2001), Productivity overshadows temperature in determining soil and ecosystem respiration across European forests, Global Change Biol., 7, 269-278, doi:10.1046/j.1365-2486.2001.00412.x.

Jobbagy, E. G., and R. B. Jackson (2000), The vertical distribution of soil organic carbon and its relation to climate and vegetation, Ecol. Appl., 10, 423-436, doi:10.1890/1051-0761(2000)010[0423:TVDOSO]2.0.CO;2.

Keeling, R. F., S. C. Piper, and M. Heimann (1996), Global and hemispheric $\mathrm{CO}_{2}$ sinks deduced from changes in atmospheric $\mathrm{O}_{2}$ concentration, Nature, 381, 218-220, doi:10.1038/381218a0.

Lavigne, M. B., et al. (1997), Comparing nocturnal eddy covariance measurements to estimates of ecosystem respiration made by scaling chamber measurements at six coniferous boreal sites, J. Geophys. Res., 102, 28,977-28,985, doi:10.1029/97JD01173.

Law, B. E., M. G. Ryan, and P. M. Anthoni (1999), Seasonal and annual respiration of a ponderosa pine ecosystem, Global Change Biol., 5, 169-182, doi:10.1046/j.1365-2486.1999.00214.x.

Lee, M.-S., K. Nakane, T. Nakatsubo, and H. Koizumi (2003), Seasonal changes in the contribution of root respiration to total soil respiration in a cool-temperate deciduous forest, Plant Soil, 255, 311-318, doi:10.1023/A:1026192607512.

Lee, X. (1998), On micrometeorological observations of surface-air exchange over tall vegetation, Agric. For. Meteorol., 91, 39-49, doi:10.1016/S0168-1923(98)00071-9.

Lee, X., H. Wu, J. Sigler, C. Oishi, and T. Siccama (2004), Rapid and transient response of soil respiration to rain, Global Change Biol., 10, $1017-$ 1026, doi:10.1111/j.1529-8817.2003.00787.x.

Liu, Q., N. T. Edwards, W. M. Post, L. Gu, J. Ledford, and S. Lenhart (2006), Temperature-independent diel variation in soil respiration observed from a temperate deciduous forest, Global Change Biol., 12 , 2136-2145, doi:10.1111/j.1365-2486.2006.01245.x.

Loescher, H. W., B. E. Law, L. Mahrt, D. Y. Hollinger, J. Campbell, and S. C. Wofsy (2006), Uncertainties in, and interpretation of, carbon flux measurements using the eddy covariance technique, J. Geophys. Res., 111, D21S90, doi:10.1029/2005JD006932.

Morén, A.-S., and A. Lindroth (2000), $\mathrm{CO}_{2}$ exchange at the floor of a boreal forest, Agric. For. Meteorol., 101, 1-14, doi:10.1016/S01681923(99)00160-4.

Morgenstern, K., T. A. Black, E. R. Humphreys, T. J. Griffis, G. B. Drewitt, T. Cai, Z. Neisic, D. L. Spittlehouse, and N. J. Livingston (2004), Sensitivity and uncertainty of the carbon balance of a Pacific Northwest Douglas-fir forest during an El Niño/La Niña cycle, Agric. For. Meteorol. 123, 201-219, doi:10.1016/j. agrformet.2003.12.003.

Ohkubo, S., Y. Kosugi, S. Takanashi, T. Mitani, and M. Tani (2007), Comparison of the eddy covariance and automated closed methods for evaluating nocturnal $\mathrm{CO}_{2}$ exchange in a Japanese cypress forest, Agric. For. Meteorol., 142, 50-65, doi:10.1016/j.agrformet.2006.11.004.

Parkin, T. B., and T. C. Kaspar (2003), Temperature controls on diurnal carbon dioxide flux: Implications for estimating soil carbon loss, Soil Sci. Soc. Am. J., 67, 1763-1772.

Peñuelas, J., T. Rutishauher, and I. Filella (2009), Phenology feedbacks on climate change, Science, 327, 887-888, doi:10.1126/science.1173004.

Post, W. M., W. R. Emanuel, P. J. Zinke, and A. G. Stangenbeger (1982), Soil carbon pools and world life pools, Nature, 298, 156-159, doi:10.1038/298156a0

Raich, J. W., and W. H. Schlesinger (1992), The global carbon dioxide flux in soil respiration and its relationship to vegetation and climate, Tellus, Ser. B, 44, 81-99.

Rannik, U., T. Markkanen, J. Raittila, P. Hari, and T. Vesala (2003), Turbulence statistics inside and over forest: Influence on footprint prediction, Boundary Layer Meteorol., 109, 163-189, doi:10.1023/A:1025404923169.

Risk, D., L. Kellman, and H. Beltrami (2008), A new method for in situ soil gas diffusivity measurement and applications in the monitoring of subsurface $\mathrm{CO}_{2}$ production, J. Geophys. Res., 113, G02018, doi:10.1029/ 2007JG000445.

Riveros-Iregui, D. A., R. E. Emmanuel, D. J. Muth, B. L. McGlynn, H. E. Epstein, D. L. Welsch, V. J. Pacific, and J. M. Wraith (2007), Diurnal hysteresis between soil $\mathrm{CO}_{2}$ and soil temperature is controlled by soil water content, Geophys. Res. Lett., 34, L17404, doi:10.1029/ 2007GL030938.

Rustad, L. E., J. L. Campbell, G. M. Marion, R. J. Norby, M. J. Mitchel, A. E. Hartley, J. H. C. Cornelissen, J. Gurevitch, and GCTE-NEWS (2001), A meta-analysis of the response of soil respiration, net nitrogen 
mineralization, and aboveground plant growth to experimental ecosystem warming, Oecologia, 126, 543-562, doi:10.1007/s004420000544.

Saigusa, N., S. Yamamoto, S. Murayama, and H. Kondo (2005), Interannual variability of carbon budget components in an AsiaFlux forest site estimated by long-term flux measurements, Agric. For. Meteorol., 134, 4-16, doi:10.1016/j.agrformet.2005.08.016.

Sampson, D. A., I. A. Janssens, J. Curiel Yuste, and R. Ceulemans (2007) Basal rates of soil respiration are correlated with photosynthesis in a mixed temperate forest, Global Change Biol., 13, 2008-2017, doi:10.1111/j.1365-2486.2007.01414.x.

Savage, K. E., and E. A. Davidson (2001), Interannual variation of soil respiration in two New England forests, Global Biogeochem. Cycles, 15, 337-350, doi:10.1029/1999GB001248.

Savage, K. E., and E. A. Davidson (2003), A comparison of manual and automated systems for soil $\mathrm{CO}_{2}$ flux measurements: Trade-offs between spatial and temporal resolution, J. Exp. Bot., 54, 891-899, doi:10.1093/ jxb/erg 121 .

Schimel, D. S., et al. (2001), Recent patterns and mechanisms of carbon exchange by terrestrial ecosystems, Nature, 414, 169-172, doi:10.1038/35102500.

Schmid, H. P. (2002), Footprint modeling for vegetation atmosphere exchange studies: A review and perspective, Agric. For. Meteorol. 113, 159-183, doi:10.1016/S0168-1923(02)00107-7.

Schneider, J., L. Ktuzbach, S. Schulz, and M. Wilmking (2009) Overestimation of $\mathrm{CO}_{2}$ respiration fluxes by the closed chamber method in low-turbulence nighttime conditions, J. Geophys. Res., 114, G03005, doi:10.1029/2008JG000909.

Schwartz, M. D. (1996), Examining the spring discontinuity in daily temperature ranges, J. Clim. 9, 803-808, doi:10.1175/1520-0442(1996) 009<0803:ETSDID>2.0.CO;2.

Staebler, R. M., and D. R. Fitzjarrald (2004), Observing subcanopy $\mathrm{CO}_{2}$ advection, Agric. For. Meteorol., 122, 139-156, doi:10.1016/j.agrformet. 2003.09.011.

Tang, J., D. D. Baldocchi, and L. Xu (2005), Tree photosynthesis modulates soil respiration on a diurnal time scale, Global Change Biol., 11, 1298-1304, doi:10.1111/j.1365-2486.2005.00978.x.
Tans, P. P., I. Y. Fung, and T. Takahashi (1990), Observational constraints on the global atmospheric $\mathrm{CO}_{2}$ budget, Science, 247, 1431-1438, doi:10.1126/science.247.4949.1431.

Trumbore, S. E., O. A. Chadwick, and R. Amundsen (1996), Rapid exchange between soil carbon and atmospheric carbon dioxide driven by temperature change, Science, 272, 393-396, doi:10.1126/science. 272.5260 .393$.

Urbanski, S., C. Barford, S. Wofsy, C. Kucharik, E. Pyle, J. Budney, K. McKain, D. Fitzjarrald, M. Czikowsky, and J. W. Munger (2007) Factors controlling $\mathrm{CO}_{2}$ exchange on timescales from hourly to decadal at Harvard Forest, J. Geophys. Res., 112, G02020, doi:10.1029/ 2006JG000293.

Valentini, R., et al. (2000), Respiration as the main determinant of carbon balance in European forests, Nature, 404, 861-865, doi:10.1038/ 35009084.

Vargas, R., and M. F. Allen (2008), Environmental controls and the influence of vegetation type, fine roots and rhizomorphs on diel and seasonal variation in soil respiration, New Phytol., 179, 460-471, doi:10.1111/ j.1469-8137.2008.02481.x.

Wofsy, S. C., M. L. Goulden, J. W. Munger, S.-M. Fan, P. S. Bakwin, B. C. Daube, S. L. Bassow, and F. A. Bazzaz (1993), Net exchange of $\mathrm{CO}_{2}$ in a mid-latitude Forest, Science, 260, 1314-1317, doi:10.1126/ science.260.5112.1314.

Zha, T., Z. Xing, K.-Y. Wang, S. Kellomäki, and A. Barr (2007), Total and component carbon fluxes of a scots pine ecosystem from chamber measurements and eddy covariance, Ann. Bot., 99, 345-353, doi:10.1093/ $\mathrm{aob} / \mathrm{mcl} 266$

J. L. Bubier, Environmental Studies Program, Mount Holyoke College, South Hadley, MA 01075, USA.

P. M. Crill, Department of Geology and Geochemistry, Stockholm University, SE-10691 Stockholm, Sweden.

S. Frolking, S. C. Phillips, and R. K. Varner, Institute for the Study of Earth, Oceans, and Space, University of New Hampshire, Durham, NH 03824, USA. (phillips.stephen.c@gmail.com)

J. W. Munger and S. C. Wofsy, School of Engineering and Applied Sciences, Harvard University, Cambridge, MA 02138, USA. 